\title{
M-I coupling across the auroral oval at dusk and midnight: repetitive substorm activity driven by interplanetary coronal mass ejections (CMEs)
}

\author{
P. E. Sandholt ${ }^{1}$, C. J. Farrugia ${ }^{2}$, and W. F. Denig ${ }^{3}$ \\ ${ }^{1}$ Department of Physics, University of Oslo, Oslo, Norway \\ ${ }^{2}$ Space Science Center, University of New Hampshire, Durham, UK \\ ${ }^{3}$ NOAA, Boulder, Colorado, USA \\ Correspondence to: P. E. Sandholt (p.e.sandholt@ @ys.uio.no)
}

Received: 2 October 2013 - Revised: 25 February 2014 - Accepted: 25 February 2014 - Published: 9 April 2014

\begin{abstract}
We study substorms from two perspectives, i.e., magnetosphere-ionosphere coupling across the auroral oval at dusk and at midnight magnetic local times. By this approach we monitor the activations/expansions of basic elements of the substorm current system (Bostrøm type I centered at midnight and Bostrøm type II maximizing at dawn and dusk) during the evolution of the substorm activity. Emphasis is placed on the R1 and R2 types of field-aligned current (FAC) coupling across the Harang reversal at dusk. We distinguish between two distinct activity levels in the substorm expansion phase, i.e., an initial transient phase and a persistent phase. These activities/phases are discussed in relation to polar cap convection which is continuously monitored by the polar cap north (PCN) index. The substorm activity we selected occurred during a long interval of continuously strong solar wind forcing at the interplanetary coronal mass ejection passage on 18 August 2003. The advantage of our scientific approach lies in the combination of (i) continuous ground observations of the ionospheric signatures within wide latitude ranges across the auroral oval at dusk and midnight by meridian chain magnetometer data, (ii) "snapshot" satellite (DMSP F13) observations of FAC/precipitation/ion drift profiles, and (iii) observations of current disruption/near-Earth magnetic field dipolarizations at geostationary altitude. Under the prevailing fortunate circumstances we are able to discriminate between the roles of the dayside and nightside sources of polar cap convection. For the nightside source we distinguish between the roles of inductive and potential electric fields in the two substages of the substorm expansion phase. According to
\end{abstract}

our estimates the observed dipolarization rate $\left(\delta B_{z} / \delta t\right)$ and the inferred large spatial scales (in radial and azimuthal dimensions) of the dipolarization process in these strong substorm expansions may lead to $50-100 \mathrm{kV}$ enhancements of the cross-polar-cap potential due to inductive electric field coupling.

Keywords. Magnetospheric physics (magnetosphereionosphere interactions)

\section{Introduction}

In the context of the development of substorm activity, the roles of different types of magnetosphere-ionosphere (M-I) current systems have been a topic of lively debate since the beginning of the space age. Bostrøm (1964) introduced the two basic elements of the substorm current system, which are often referred to as Bostrøm type I and II currents. The Bostrøm type I system is commonly applied to the coupling via R1 field-aligned current (FAC) between the cross-tail current (CTC) of the plasma sheet and a westward-directed electrojet current (WEJ) along the auroral oval, centered near midnight. The latter curent system is often referred to as the substorm current wedge (SCW) (McPherron et al., 1973; Lyons et al., 2003; Sergeev et al., 2011). Bostrøm type II is, on the other hand, often applied to the coupling between the partial ring current and northward (southward)-directed currents in the ionosphere via R2 FACs at dusk (dawn). This coupling maximizes near the equatorward boundary of the 
auroral oval in the dusk-to-premidnight and postmidnight-todawn sectors (Bostrøm, 1977).

The activation of these two types of current system during the substorm process leads to distinct auroral phenomena: (i) breakup of the most equatorward auroral arc (MEA) in the midnight sector, followed by (ii) auroral expansions (northsouth and east-west), as described by Akasofu (1964), and (iii) sequential activations of the auroral poleward boundary (poleward boundary intensifications, or PBIs) followed by equatorward-moving auroral streamers (Henderson et al., 1998; Lyons et al., 1999; Fairfield et al., 1999; Sandholt et al., 2002).

While the poleward auroral expansion may be explained by an "in-out" motion of a current disruption (magnetic field dipolarization) in the plasma sheet (Baumjohann et al., 1999; Akasofu, 2013), feature ii (auroral streamer events) is related to the "out-in" motion of plasma-depleted flux tubes (Chen and Wolf, 1993) characterized by magnetic field dipolarization fronts and bursty bulk flows (BBFs) (Henderson et al., 1998; Fairfield et al., 1999; Lyons et al., 2012; Sergeev et al., 2012). Here we shall study low-altitude manifestations of the dynamic plasma sheet-ring current system in the form of eastward electrojet (EEJ)/WEJ activations and associated $\mathrm{FAC} /$ precipitation events appearing on either side of the Harang reversal boundary at the peak of a major magnetic storm. As an introduction to the detailed auroral electrodynamics of the Harang region we refer to Marghitu et al. (2009) and references therein. We shall adopt the definition of the Harang region used by Marghitu et al. (2009): "By the Harang region (HR) we understand that part of the auroral oval where the eastward electrojet (EEJ) at lower latitudes coexists with the westward electrojet (WEJ) at higher latitudes." This definition follows the tradition from the original work of Harang (1946) and Heppner (1972).

The Harang region, normally located in the premidnight sector, is considered to be a most interesting region for the investigation of ionospheric signatures of substorm dynamics (Lyons et al., 2003; Zou et al., 2009). This is the sector of the auroral oval where most vigorous $\mathrm{M}-\mathrm{I}$ coupling processes involving R1 and R2 FACs are expected to take place during substorm activity (Koskinen and Pulkkinen, 1995; Lyons et al., 2003; Weygand et al., 2008; Zou et al., 2009; Nishimura et al., 2010). Thus, the Harang region is a key locus of magnetospheric convection currents where ionospheric closures of both Bostrøm type I and II currents appear along the same magnetic local time (MLT) meridian.

The ultimate goal of the present study is to improve on our knowledge of the detailed temporal evolution of repetitive substorm activity driven by interplanetary coronal mass ejections (CMEs) with emphasis on these three substorm elements: (1) activation of the SCWs (Bostrøm type I current system) with associated westward auroral electrojet (WEJ of Cowling channel type) current; (2) activation of Bostrøm type II current systems with electrojets at dawn (WEJ) and dusk (EEJ); and (3) activation of current wedgelets associated with BBFs. The main focus of our investigation is on the evolution of these current systems during the substorm-storm phases, as monitored by the auroral electrojet index AL and the ring current index SYM-H, respectively, and the associated excitation of polar cap convection. Processes 2 and 3 will be monitored from groundsatellite conjunctions across the auroral oval at dusk. In the present case information on phenomenon 1 is obtained from the AL index (and Alaska magnetograms) in combination with plasma/field data from the magnetospheric probe GOES-10 (Geostationary Operational Environmental Satellite), moving at geostationary heights from dusk through midnight to dawn.

The M-I coupling from the inner edge of the plasma sheet-partial ring current is expected to intensify during the conditions we study, i.e., repetitive substorm activity during magnetic storms excited by interplanetary CMEs. In this study we document the temporal variability of this coupling based on ground-satellite conjunctions along the 18:00 MLT meridian in different phases of the substorm-storm evolution. This sector of the auroral oval is typically occupied by the EEJ and Bostrøm type II arcs (Marklund, 1984; Kauristie et al., 2001). However, as we shall see, during certain substorm conditions the WEJ may expand westward into the 17:00-18:00 MLT sector. This condition of repetitive westward expansions-eastward retractions of the Harang region at dusk is a central feature of our observations.

This type of substorm activity is different from isolated substorms appearing during more typical interplanetary conditions in that the present activity may not show the standard evolution of substorm phases growth-expansion-recovery (Farrugia et al., 1993; Klimas et al., 2000; Henderson et al., 2006; Troshichev and Janzhura, 2009; Sandholt et al., 2012; Akasofu, 2013). Most notable is the absence of a full recovery of the substorm activity. Thus, each major AL excursion is accompanied by a partial recovery.

Yagodkina et al. (2012) reported global auroral distribution and oval boundary motions during interplanetary CME conditions similar to those we study. The northern and southern branches of the double oval configuration (Northern Hemisphere) were found to be characterized by discrete and diffuse precipitations, respectively (see also Vorobjev et al., 2013). In the Harang region this difference corresponds to our distinction between Harang region-north occupied by the WEJ and Harang region-south (HR-S) characterized by the EEJ. The width of the two auroral branches were found by Yagodkina et al. (2012) to depend on the storm intensity, as measured by the Dst index.

The response of polar cap convection (as reflected in the PCN index; see Troshichev et al., 2000) during the substormstorm evolution, as measured by the AL and SYM-H indices, is an important aspect of the present study. Furthermore, we aim at distinguishing between the dayside and nightside sources of polar cap convection. As we shall see, this is a nontrivial task when the dayside source is also variable. 
The type of strong AL events we study is expected to be associated with deep plasma injections into the partial ring current (see e.g. Henderson et al., 2006, and Burke et al., 2007). According to the modeling work of Yang et al. (2012) and Birn and Hesse (2013) and the experimental study of Frissell et al. (2011) such deep inward penetration of the plasma-depleted flux tubes may contribute to the partial ring current and associated R2 FAC coupling to the ionosphere. In MHD studies it has been shown that shears in the azimuthal flows near the plasma sheet-partial ring current interface can give rise to R1 and R2 polarity FACs at the outer and inner edges of the intruding plasma bubbles (Birn and Hesse, 2013). We shall study associated signatures in the expanded Harang region at dusk. The appearance of auroral streamers on the poleward boundary of the auroral oval in the Harang region has been reported by Sandholt et al. (2002) and Lyons et al. (2012). Earthward-moving flow bursts in the plasma sheet-partial ring current system are expected to give rise to specific ionospheric signatures appearing on both sides of the Harang reversal boundary. In this study we extend previous work on these magnetotail phenomena by our ground-satellite conjunction observations along the 18:00 MLT meridian. Related to this we note that PBIs and auroral streamers may be taken as signatures of ongoing magnetotail reconnection with associated BBFs (see e.g. Sergeev et al., 2012).

Figure 1 shows a sketch of the Harang region in the dusk (left)-to-premidnight sector of the auroral oval placed in a larger ionosphere-magnetosphere context. Indicated are EEJ/WEJ currents on the equatorward and poleward sides of the Harang reversal boundary (marked HRB in the figure), R1 and R2 FACs with ionospheric closure currents, and auroral phenomena such as PBIs and equatorward-moving auroral streamers emanating from PBIs. M-I coupling via three types of current systems applicable to substorms is illustrated: Bostrøm type I system in two variants (SCW and wedgelets-BBFs) and Bostrøm type II system on the dusk and dawn sides. The Bostrøm type I current system is activated on the magnetospheric side by disruptions of the CTC. Bostrøm type II current systems may be activated by dynamo action $(\boldsymbol{E} \cdot \boldsymbol{J}<0)$ in flow braking regimes $\left(\boldsymbol{J}_{\text {perp }} \times \boldsymbol{B}\right.$-force $)$ near the plasma sheet-ring boundary, as indicated in the figure (see Birn and Hesse, 2013). We note that the R2 FAC in the Bostrøm type II system configures as east-west aligned current sheets in the dusk-to-premidnight and postmidnightto-dawn sectors (see Bostrøm, 1977, his Fig. 8). Events of plasma intrusion from the midtail followed by diversion closer to Earth (as indicated in the figure; see also McPherron et al., 2011) and association with auroral arc brightening have been recently documented by Yau et al. (2013). On the relationship between the Harang reversal boundary and the substorm injection boundary we refer to the early study by Brekke (1977). The indicated ionospheric closure of R2 FAC at subauroral latitudes (eastward-directed ionospheric current) has been demonstrated by Ritter and Lühr (2008).

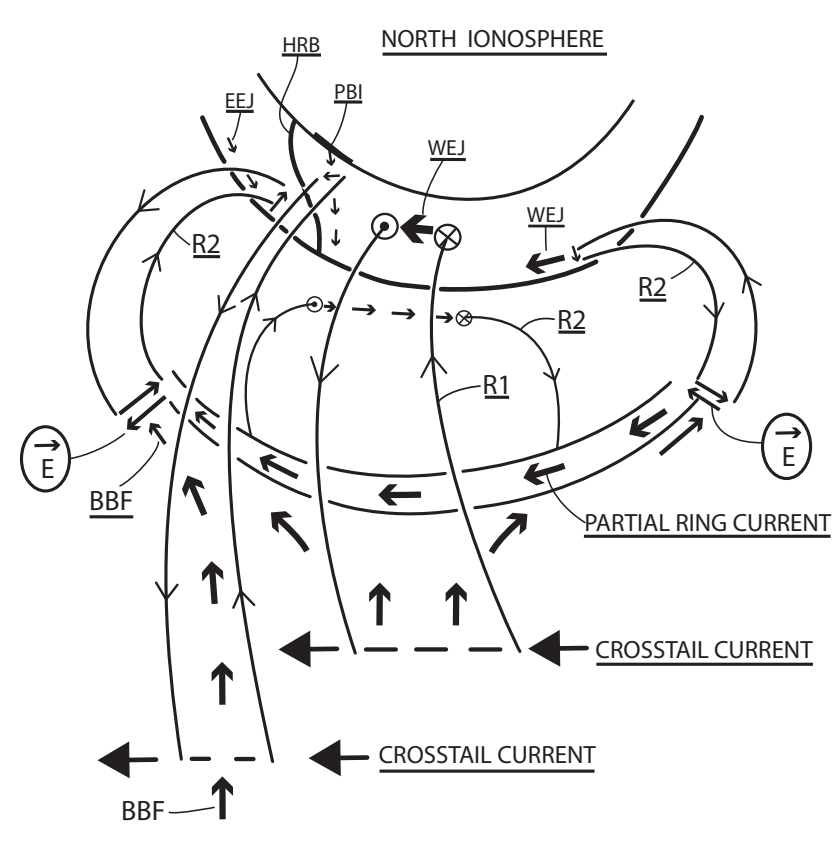

MAGNETOTAIL

Fig. 1. Schematic illustration of $M-I$ coupling via three categories of current systems applicable to substorms: Bostrøm type 1 in two variants (substorm current wedge, $\mathrm{SCW}$, in the midnight sector and wedgelets related to BBFs) and Bostrøm type 2 currents on the dusk and dawn sides. Ionospheric Pedersen current closures of R1 and R2 FACs across the Harang reversal boundary (HRB) with their connections to the magnetosphere are indicated. The Bostrøm type I systems are powered by earthward-directed plasma intrusions and disruptions of the cross-tail current (CTC) giving rise to R1-type FACs. Bostrom type II systems are powered by plasma intrusion to the plasma sheet-partial ring current boundary and channels of flow braking $\left(\boldsymbol{J}_{\text {perp }} \times \boldsymbol{B}-\right.$ force) representing dynamo action $(\boldsymbol{E} \cdot \boldsymbol{J}<0)$ with associated excitation of field-aligned current (FAC) sheets. Connections with westward and eastward electrojets (WEJ/EEJ) in the ionosphere (after Bostrøm, 1977) are indicated as well as ionospheric closure of R2 FAC at subauroral latitudes (eastwarddirected ionospheric current).

Our definition of substorm activity as illustrated in Fig. 1 involves the following basic elements: (i) disruption of the CTC in the near-Earth PS (magnetic field dipolarizations seen at geostationary altitude) leading to the activation of the SCW (Bostrøm type I current system; see McPherron et al., 1973), followed by (ii) plasma intrusion to the partial ring current with activation of the injection dynamo $(\boldsymbol{E} \cdot \boldsymbol{J}<0$; see e.g. Tanaka et al., 2010, and Yau et al., 2013) with associated Bostrøm type II current systems at dusk and dawn, (iii) M-I coupling at subauroral latitudes giving rise to SYM-H partial recovery, and (iv) the presence of BBFs with ionospheric signatures on both sides of the Harang reversal boundary in the later phase of the substorm expansion (persistent phase-partial recovery). 
Under periods of moderate disturbance the Harang reversal boundary lies in the premidnight sector. Thus, at 18:00 MLT the auroral oval is typically occupied only by the EEJ (see e.g. Kauristie et al., 2001, and Gjerloev and Hoffman, 2001). However, during the expansion phase of certain substorm activities, including the category we discuss in this paper (see e.g. Cai et al., 2006; Henderson et al., 2006; and Andalsvik et al., 2011), the WEJ and the Harang reversal boundary expand westward across the 18:00 MLT meridian (Andalsvik et al., 2011), as we shall also demonstrate below. According to Nielsen and Greenwald (1979) the Harang discontinuity (our Harang reversal boundary) tended to be observed by the Stare radar in the 21:00-24:00 MLT sector, but it was observed as early as 18:30 MLT under very disturbed conditions. Below we shall document the presence of the Harang reversal boundary in DMSP F13 data at 17:00 MLT under the conditions we study, i.e., long-lasting repetitive substorm activity ( $\mathrm{AL}=-1400 \mathrm{nT})$ driven by a geoeffective interplanetary CME. The type of extended Harang region (extreme WEJ expansions) we observe is consistent with the observations of Henderson et al. (2006) and Troshichev et al. (2011) during sawtooth substorms, i.e., substorms recurring at $2-3 \mathrm{~h}$ intervals during strong solar wind (SW) forcing conditions.

In this paper we study the evolution of M-I coupling during repetitive substorm activity by monitoring manifestations of two basic current systems (Bostrøm types I and II) in two different MLT sectors: (i) M-I coupling in the midnight sector (20:00-03:00 MLT) based on magnetic field dipolarizations at geostationary altitude versus WEJ activity across the oval at midnight; and (ii) M-I coupling along the magnetic meridian in the 17:00-18:00 MLT sector, across the Harang region, by ground-satellite conjunction studies. We distinguish between two distinct substages of the substorm expansion phase, namely, an initial transient phase and a persistent phase. This is based on the character of the electrojet activity (AL index; magnetograms at dusk and midnight). Corresponding responses in polar cap convection (PCN index) are investigated. We note the presence of (i) rapid monotonic rise versus (ii) fluctuating, stable or decreasing PCN index in the transient and persistent phases, respectively. The available multi-instrument and multisite observations allow us to discriminate between the dayside and nightside sources of the PCN response. For the nightside source we discuss the roles of inductive and potential electric fields in M-I coupling in the two mentioned substages of the substorm expansion phase. Thus, we aim at increasing our understanding of the convection sources of the polar cap index.

Continuous ground observations of magnetic deflections at dusk are obtained by the IMAGE chain of magnetometers in Svalbard, Scandinavia, Finland, and Russia (www. geo.fmi.fi/image). This magnetometer chain covers a wide latitude range from subauroral latitudes to the polar cap. Direct observations of the two substorm current branches coupled to the EEJ and WEJs, in the form of FACs and

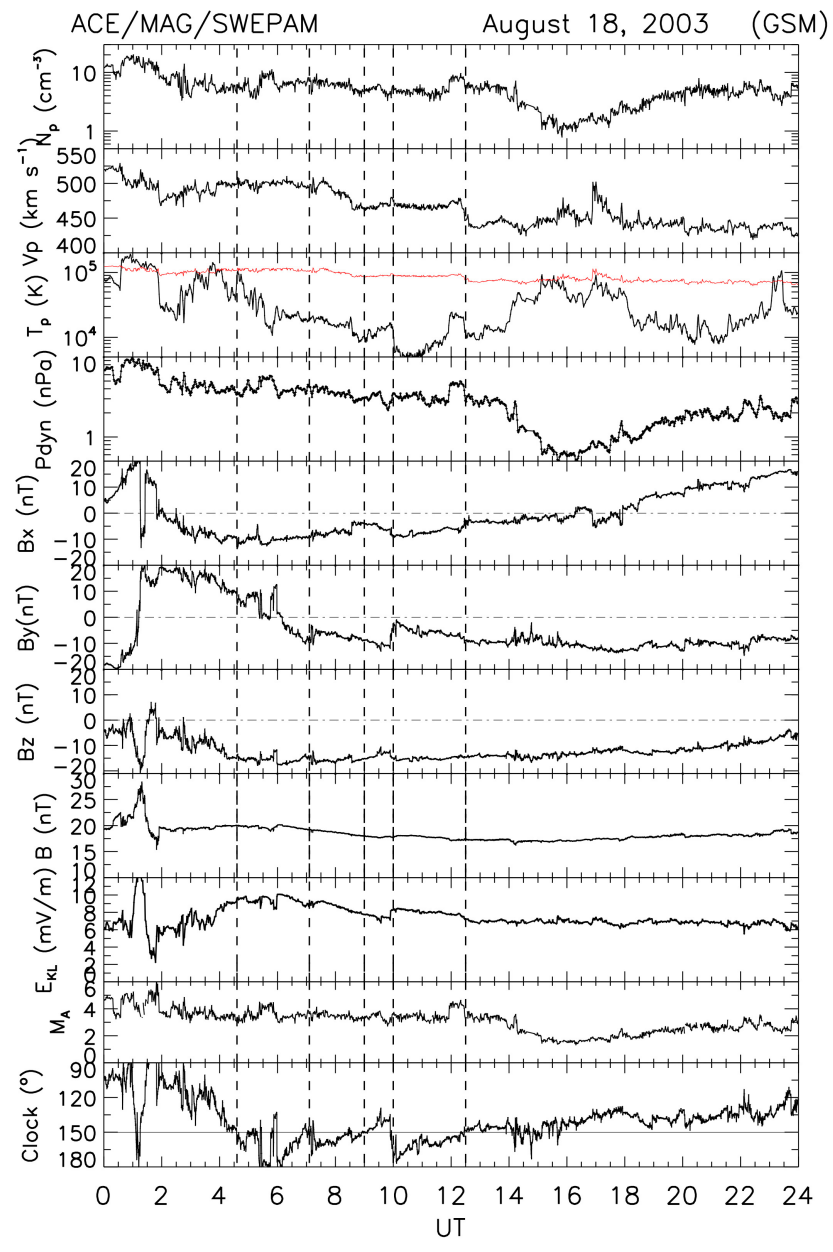

Fig. 2. Interplanetary data from spacecraft Advanced Composition Explorer (ACE). Panels from top to bottom show proton density $\left(N_{\mathrm{p}} ; \mathrm{cm}^{-3}\right)$; bulk speed $\left(V_{\mathrm{p}} ; \mathrm{km} \mathrm{s}^{-1}\right)$; proton temperature $T_{\mathrm{p}}(\mathrm{K}$; in red the expected temperature after Lopez and Freeman, 1986); dynamic pressure $P_{\text {dyn }}(\mathrm{nPa})$; magnetic field components $B_{x}, B_{y}$ and $B_{z}$ in GSM coordinates; the field strength $B(\mathrm{nT})$; the Kan-Lee merging electric field $E_{\mathrm{KL}}\left(\mathrm{mV} \mathrm{m}^{-1}\right)$; the Alfvén Mach number $M_{\mathrm{A}}$; and the clock angle of the magnetic field $\left(^{\circ}\right)$. Different field orientations (clock angle regimes) are marked by vertical dashed guidelines.

particle precipitation, are obtained from DMSP F13 passes across the oval at dusk. The UT interval we study is determined by the fact that the IMAGE chain of magnetometers typically enter the Harang region at $\sim 14: 30-16: 00$ UT ( 17:00-18:00 MLT) under the strong solar wind forcing conditions we study (Andalsvik et al., 2011, 2012; Sandholt et al., 2012).

The spatial-temporal evolution of the nightside WEJ is monitored by Alaska chain magnetograms covering the latitude range from 63 to $69^{\circ}$ magnetic latitude (MLAT) in the 19:00-01:00 MLT sector (06:00-12:00 UT). 


\section{Data description}

Figure 2 shows interplanetary magnetic field and plasma data from spacecraft ACE on 18 August 2003. The panels show, from top to bottom, the proton density, bulk speed, temperature (in red: expected proton temperature after Lopez and Freeman, 1986), the dynamic pressure, the Geocentric Solar Magnetospheric (GSM) components of the magnetic field and the total field, the Kan-Lee merging electric field $E_{\mathrm{KL}}$ (Kan and Lee, 1979), and the clock angle, i.e., the polar angle in the GSM $y-z$ plane. $E_{\mathrm{KL}}=V B_{T} \sin ^{2}(\theta / 2)$, where $V$ is the solar wind bulk speed, $B_{T}=\left(B_{y}^{2}+B_{z}^{2}\right)^{1 / 2}$, and $\theta$ is the clock angle $\left(180^{\circ}\right.$ meaning due south IMF; $B_{y}<0$ regime corresponds to westward component).

The data correspond to the passage at Earth of a longduration interplanetary CME lasting from 01:00 UT on 18 August until 15:00 UT on 19 August (Richardson and Cane, 2010). Noteworthy are (i) the highly variable dynamic pressure; (ii) the magnetic field vector, which after an initial rotation settles to values of $B_{z} \sim-15 \mathrm{nT}$ and $B_{y} \sim-10 \mathrm{nT}$ with corresponding smoothly decreasing clock angle to the range (150-120 $)$; and most importantly (iii) the high values of the merging electric field, settling later in the day to values of $\sim 7 \mathrm{mV} \mathrm{m}^{-1}$ and the low Alfvén Mach number (2-5) compared to typical solar wind values $(\sim 8-10)$.

During the central time interval of our study (12:0016:00 UT) $P_{\text {dyn }}$ decreases from 5 to $<1 \mathrm{nPa}$ due to the decreasing density. The magnetic field lies essentially in the $y-z$ plane $\left(B_{x}<3 \mathrm{nT} ; B_{y} \sim-10 \mathrm{nT} ; B_{z} \sim-15 \mathrm{nT}\right.$; clock angle decreasing from 150 to $120^{\circ}$ ). The bulk speed is $\sim 450 \mathrm{~km} \mathrm{~s}^{-1}$.

A major difference between the intervals 04:00-12:00 and 12:00-18:00 UT (our detailed study) is the presence of subintervals when the clock angle is between 150 and $180^{\circ}$ in the former. This is associated with higher $E_{\mathrm{KL}}$ values (8$10 \mathrm{mV} \mathrm{m}^{-1}$ ) and, as we shall see below, higher peaks of the PCN index. We also note the abrupt increases of the clock angle (to $180^{\circ}$ ) and $E_{\mathrm{KL}}$ (from 7 to $8.5 \mathrm{mV} \mathrm{m}^{-1}$ ) at 10:00 UT. Below we shall see that this leads to a convection increase at the dayside polar cap boundary at $\sim$ 11:00 UT, as monitored by ground magnetometers. This is consistent with a propagation delay from $\mathrm{ACE}$ to the magnetopause of $\approx 60 \mathrm{~min}$. ACE was located at $(228,-34,13) R_{\mathrm{E}}$.

Figure 3 shows the geomagnetic indices AL (nT) and PCN $\left(\mathrm{mV} \mathrm{m}^{-1}\right)$ for the whole day (18 August 2003). PCN is a measure of the equivalent convection in the central polar cap of the Northern Hemisphere (Troshichev et al., 2000). The entire data set is from the Northern Hemisphere. The PCN index is sensitive to both dayside and nightside convection sources (Kullen et al., 2009; Gao et al., 2012; Sandholt et al., 2012). The interval from 04:00 to 20:00 UT is characterized by a series of major AL excursions each of which maximizes at values of -1000 to $-1600 \mathrm{nT}$, marked by vertical guidelines. Each large AL excursion (initial transient phase) is followed by a persistent phase and a partial recovery to

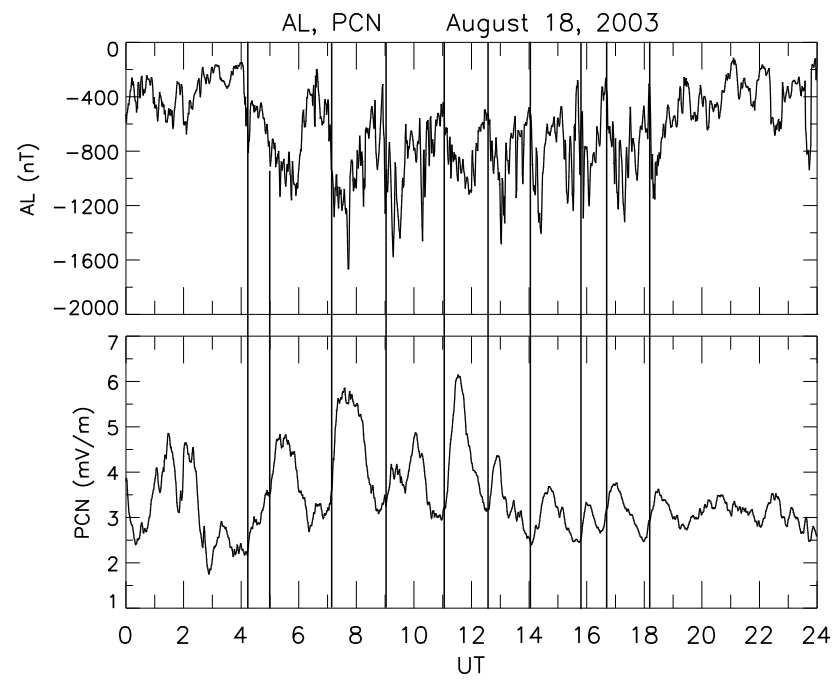

Fig. 3. $\mathrm{AL}(\mathrm{nT})$ and $\mathrm{PCN}\left(\mathrm{mV} \mathrm{m}^{-1}\right)$ indices for 18 August 2003. Onsets of AL excursions and corresponding PCN enhancements are marked by vertical guidelines.

values within -400 to $-600 \mathrm{nT}$. In subinterval I (04:0012:00 UT) these events recur at $2-3 \mathrm{~h}$ intervals. In interval II (12:00-18:00 UT) major AL excursions recur at shorter $(\sim 1 \mathrm{~h})$ intervals. These AL events are accompanied by corresponding PCN enhancements. The PCN index thus reveals a pulsed mode of polar cap convection. We note that the change from larger to shorter recurrence times at 12:00 UT is accompanied by a change from higher $\left(5-6 \mathrm{mV} \mathrm{m}^{-1}\right)$ to lower $\left(3.5 \mathrm{mV} \mathrm{m}^{-1}\right) \mathrm{PCN}$ peak amplitudes. Related to this is the higher background (minimum value between the peaks) PCN level in interval I $\left(3 \mathrm{mV} \mathrm{m}^{-1}\right)$ compared to interval II $\left(2.5 \mathrm{mV} \mathrm{m}^{-1}\right)$. This may be due to a correspondingly higher level of $E_{\mathrm{KL}}$ (dayside source) in this interval (see Fig. 2).

The relatively stable $E_{\mathrm{KL}}$ in this case (decreasing slowly from 10 to $7 \mathrm{mV} \mathrm{m}^{-1}$ during the subinterval 06:00-12:00 UT and remaining very stable thereafter from 12:00 onwards) makes it generally easy to distinguish between the dayside (magnetopause reconnection) and nightside (magnetotail reconnection) sources of polar cap convection in such cases.

In these activity series we distinguish between (i) an initial transient phase (initial, abrupt AL excursion) followed by (ii) a persistent phase characterized by a persistent high AL activity (see interval 04:00-12:00 UT) and (iii) a reduced AL deflection in the phase of partial recovery. A correspondence to this AL behavior is seen in the PCN index: (i) initial monotonic rise, followed by (ii) persistent high PCN values, and (iii) decrease to the background level. Later we shall discuss the specific PCN increase during the interval 11:00 to 11:40 UT (with PCN maximum at $6 \mathrm{mV} \mathrm{m}^{-1}$ ) from the perspective of the dayside and nightside convection sources. A dayside contribution is expected in view of the abrupt $E_{\mathrm{KL}}$ enhancement recorded by ACE at $\sim 10: 00$ UT. 

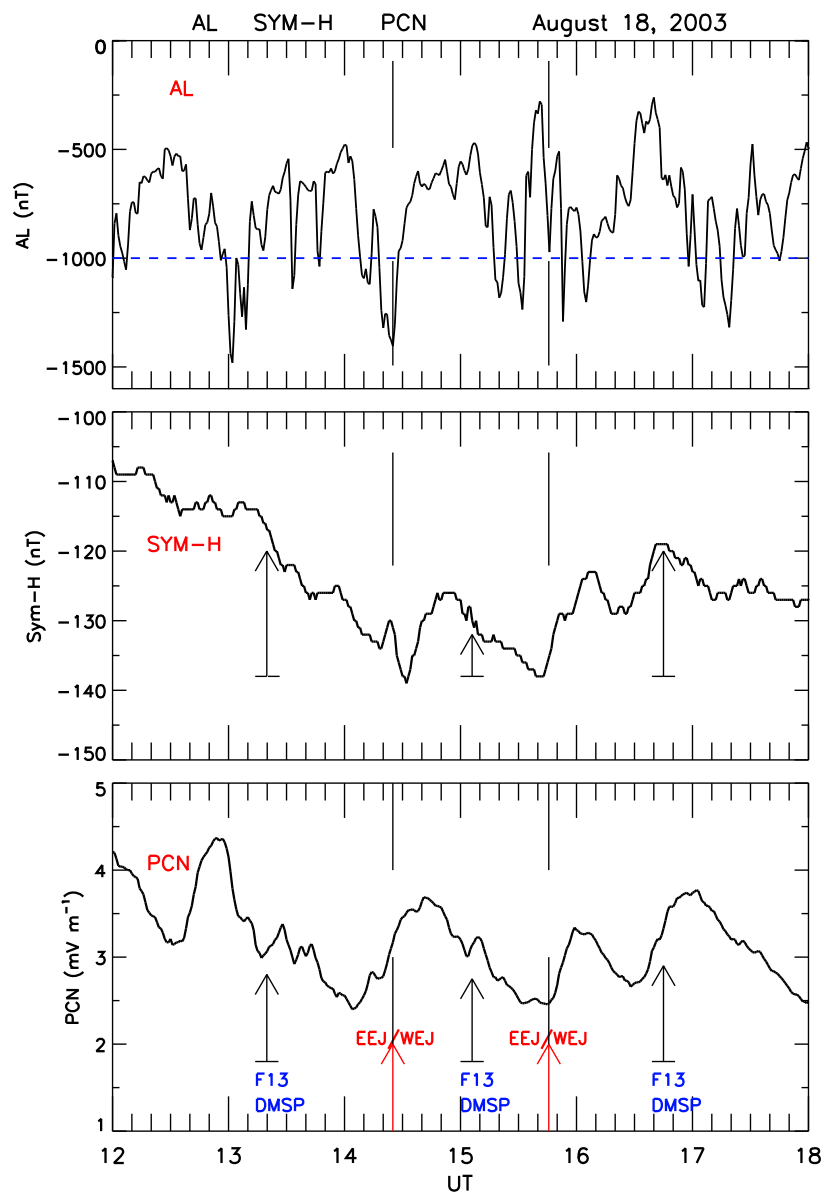

Fig. 4. AL-SYM-H-PCN indices for the interval 12:00-18:00 UT. Three passes of spacecraft DMSP F13 across the oval at dusk $(13: 26,15: 09,16: 46 \mathrm{UT})$ are marked by arrows. Two major EEJ/WEJ events at dusk (14:20 and 15:45 UT) are marked by vertical dashed lines.

Figure 4 shows a plot of the three indices AL (top), SYM$\mathrm{H}$, and PCN (bottom). Three passes of spacecraft DMSP F13 across the oval at dusk $(13: 26,15: 09,16: 46 \mathrm{UT})$ are marked by arrows. Two major EEJ/WEJ events at dusk (14:20 and 15:45 UT), as inferred from the IMAGE chain magnetometer data (see below), are marked by vertical dashed lines.

A pattern of repetitive events consisting of (i) major AL events followed by SYM-H dips and (ii) intervals of partial recoveries in both parameters are identified. Thus, from these plots we distinguish between two levels of the AL activity: (i) major $\mathrm{AL}$ events (AL minima within -1000 to $-1500 \mathrm{nT}$ ) and (ii) AL partial recovery (repetitive AL events within -400 to $-1000 \mathrm{nT}$ ). We also note the PCN enhancements in the phase of SYM-H partial recovery. Major ALPCN events recur at $\sim 1 \mathrm{~h}$ intervals.

The two first satellite passes (13:26 and 15:09 UT, marked F13) occurred at the time of $|\mathrm{SYM}-\mathrm{H}|$ increases, while the third pass (at 16:46 UT) occurred in a phase of |SYM-H| partial recovery (see middle panel). Below we shall document the different states of M-I coupling in Harang region-north and Harang region-south during the satellite traversals across the auroral oval at dusk corresponding to these different phases of SYM-H activity.

Figure 5 shows particle precipitation, ion drift and magnetic deflections (FAC signatures) during a dusk-to-dawn crossing of the oval and polar cap by satellite DMSP F13 in the interval 13:18-13:45 UT. From the precipitation data we note the presence of a double auroral configuration across both the dusk and dawn sectors of the oval. The high-latitude branch of the aurora at dusk corresponds to the regime of westward electrojet (antisunward convection) which we refer to as Harang region-north. At 13:25 UT Harang regionnorth is located within $69-72^{\circ}$ MLAT. This regime is characterized by an outward-directed FAC (negative $\Delta B_{z}$ gradient). This is the expected FAC polarity at the western edge of the westward electrojet in a Bostrøm type I current configuration (Marghitu et al., 2009) (see Fig. 1). The polar cap boundary is identified as the abrupt transition from the auroral oval to polar rain precipitation (Fairfield and Scudder, 1985) at $\sim 72^{\circ}$ MLAT (13:26:20 UT).

The southern branch of the aurora, containing intense electron and ion fluxes within $\sim 60-63^{\circ}$ MLAT, is accompanied by large positive (at equatorward boundary) and negative (further north) $\Delta B_{z}$ gradients. The steep positive gradient near the equatorward boundary indicates an intense, concentrated R2 FAC flowing into the ionosphere. We note that this satellite crossing of the bipolar FAC system within 57-62 ${ }^{\circ}$ MLAT (17.2 MLT) occurred at the time (13:22 UT) of increasing SYM-H deflection (partial ring current monitor; see Fig. 4) and a clear positive $X$ deflection at IMAGE station NUR ( $57^{\circ}$ MLAT; see below), indicating enhanced EEJ activity. Northward-directed ionospheric Pedersen current closure of the R2 FAC, possibly giving rise to the EEJ, is marked by the horizontal arrow in the bottom panel. The observed bipolar FAC system in Harang region-south is that which is schematically indicated in Fig. 1.

Figure 6 shows F13 data for the next crossing of the oval at dusk within the interval 15:03:00-15:08:10 UT. Combining precipitation and cross-track ion drift data, we identify clear signatures of Harang region-south and Harang regionnorth at 17.5 MLT, as marked in the figure. As on the previous pass the F13 crossing of Harang region-south during 15:03-15:05 UT occurred in a phase of increasing SYM-H deflection (see Fig. 4). We note (i) the strong R2 FAC intensity (large positive $\Delta B_{z}$ gradient marked by solid arrow) at the equatorward boundary of the southern auroral branch (Harang region-south), (ii) a similarly strong negative gradient further north in Harang region-south (solid arrow), and (iii) the R1-type FAC structures and inverted-V type electron precipitations within Harang region-north. In the most intense of the latter events we do see a FAC and ion drift configuration (flow channel on the poleward side of outwarddirected FAC) which is similar to that typically associated with auroral streamer events (see e.g. Sergeev et al., 2004). 


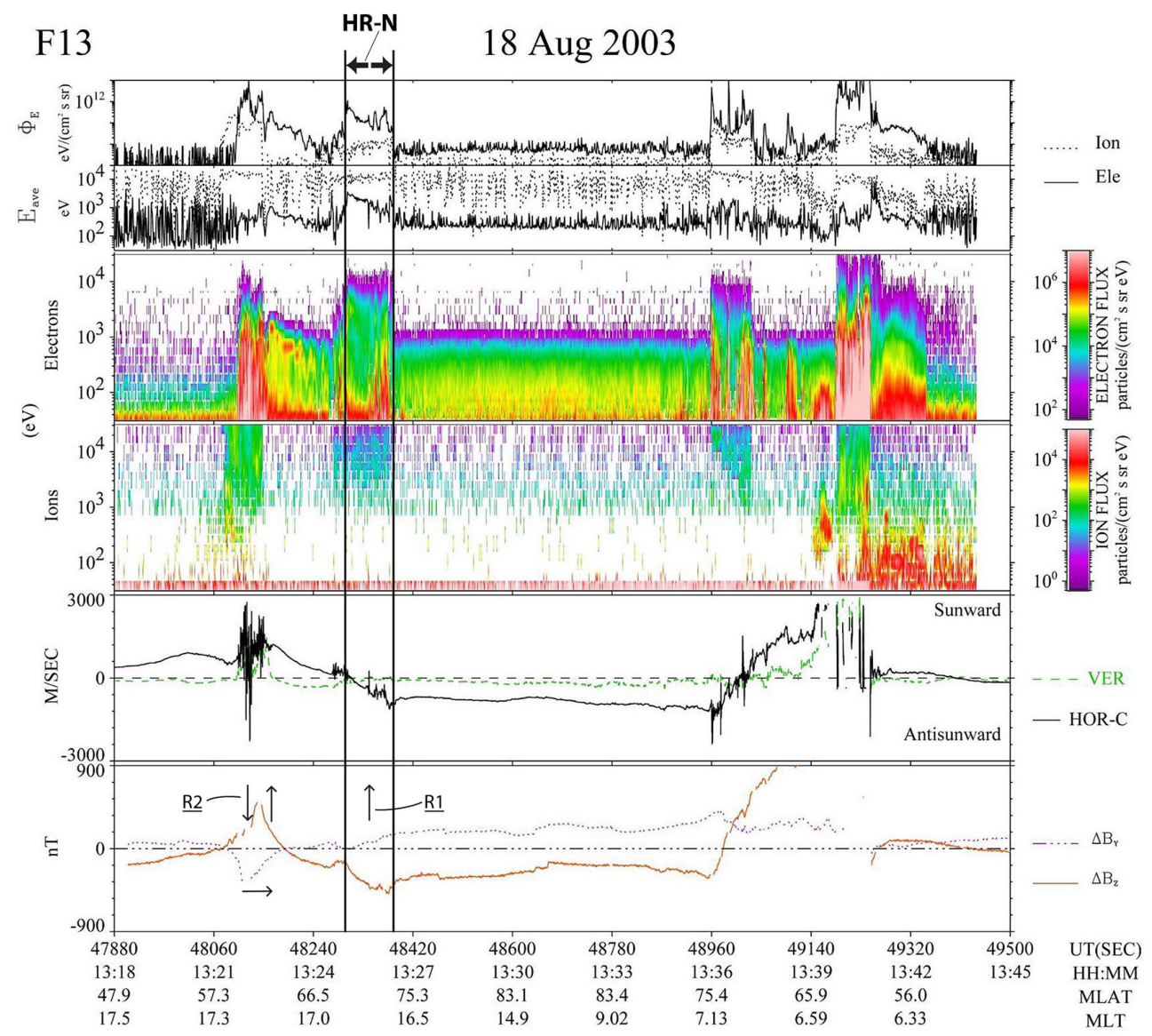

Fig. 5. DMSP F13 data for the dusk-to-dawn traversal of the oval-polar cap - oval during the interval 13:18-13:45 UT. Panels from top to bottom shows (i) electron (ion) energy flux, (ii) electron (ion) average energy, (iii) electron spectrograms, (iv) ion spectrograms, (v) crosstrack ion drift (horizontal component in black trace), (vi) $\Delta B_{y}$ and $\Delta B_{z}$ (yellow). The regime of antisunward convection and northern auroral branch at dusk (Harang region-north; HR-N) is marked by vertical guidelines. Regimes of enhanced FAC intensity are marked by vertical arrows in the bottom panel.

The association between the downward-directed R2 FAC, the ionospheric Pedersen current closure (indicated by horizontal arrow in the lower panel) and the EEJ is as expected from the Bostrøm type II current configuration. The electron precipitation in HR-S shows rather broad-banded energy spectra, which is a typical result of Alfv́en-wave acceleration (e.g. Haerendel, 2011).

These observations in Harang region-north are relevant in view of this statement by Haerendel (2011): "In the case of auroral streamers we have a deplorable lack of electromagnetic data on the arcs and flow channels." Below we shall document the ground magnetic signature of the auroral event (inverted-V type arc at 17.5 MLT) traversed by DMSP F13 at 15:07 UT.

Figure 7 shows F13 data from an oval crossing from south to north at dusk (17.9 MLT) within the interval 16:4016:52 UT. This F13 crossing of the oval equatorward boundary at dusk (16:43 UT) occurred at the time of a maximum partial recovery of the SYM-H index, just before a new
SYM-H dip appeared (see Fig. 4). Thus we infer that this pass occurred near the western boundary of a retracted HR and WEJ. The oval at dusk is in this case occupied by the regime of EEJ (sunward convection). Compared to the other two passes reported above, the R2 FAC is a very weak R2 (small $\Delta B_{z}$ gradient). Absent is the strong R2 FAC (steep positive $\Delta B_{z}$ gradient) observed at the oval equatorward boundary in the two previous passes.

The oval poleward boundary (polar cap boundary) at 70.8 $8^{\circ}$ MLAT/17.9 MLT (16:48 UT) is characterized by two discrete arcs (accelerated electron populations), a fluctuating ion drift signature (sunward-antisunward-sunwardantisunward) and associated two-component outwarddirected Birkeland current structure. High-resolution data show a narrow regime of antisunward convection reaching $2 \mathrm{~km} \mathrm{~s}^{-1}$ in the close vicinity of the energetic arc. This aurora-FAC-ion drift configuration is observed at the polar cap boundary near the western edge of the WEJ-SCW (see Fig. 1 and Marghitu et al., 2009). The double arc (with 


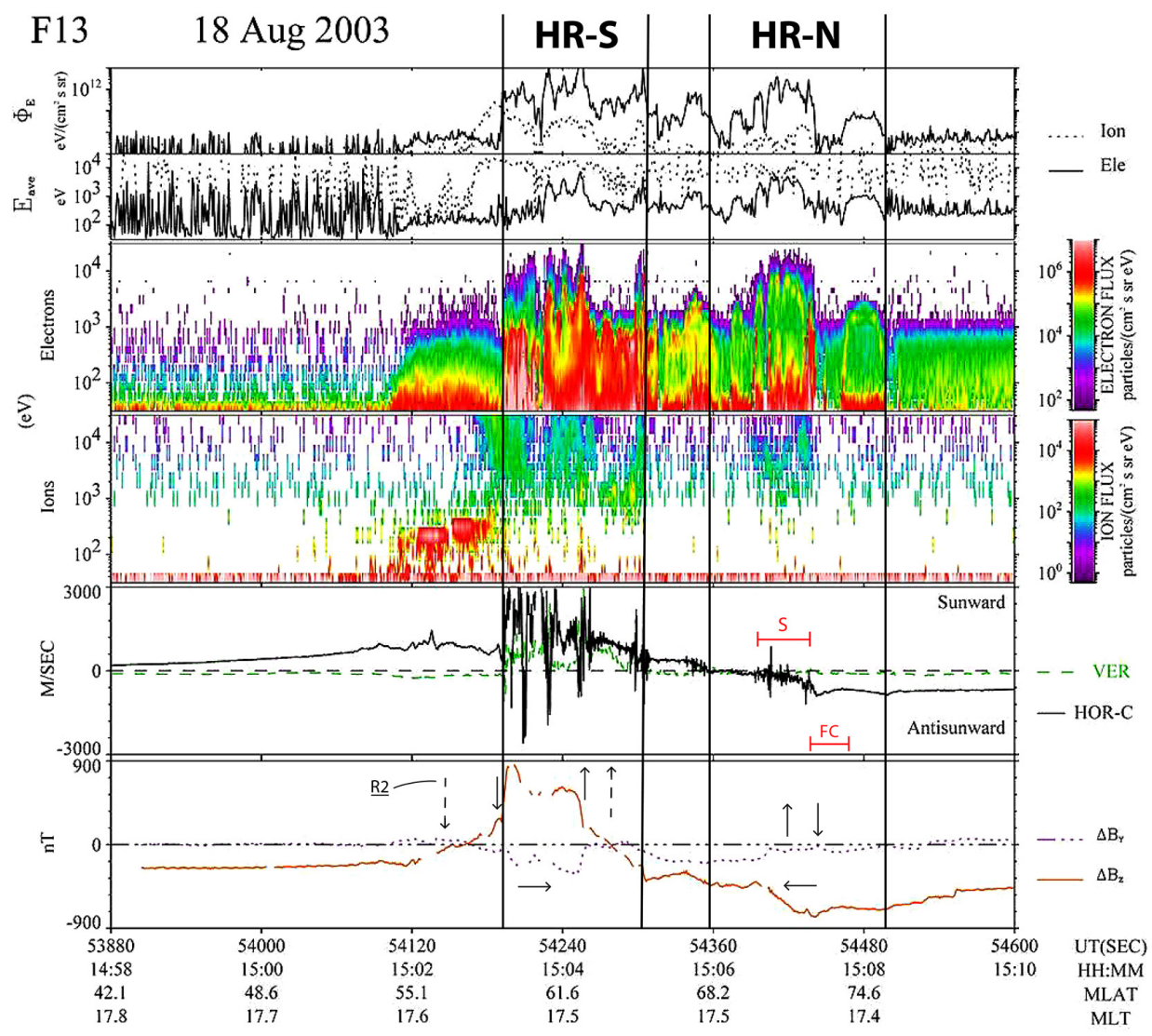

Fig. 6. DMSP F13 data for the traversal of dusk-side auroral oval (17.5 MLT) from south to north during the interval 15:03-15:08:10 UT. Same format as in Fig. 5. The latitude regimes Harang region-south and Harang region-north are marked by vertical guidelines. Major features of the FAC configuration are indicated by vertical arrows in the bottom panel. Auroral streamer (S) precipitation and associated flow channel (FC) in HR-N are marked in the ion drift panel.

corresponding two-component FAC structure) is interesting in view of certain studies emphasizing the favorable conditions for interhemispheric FAC adjacent to the traditional R1 current near the PC boundary in the northern hemispheric summer (Benkevich et al., 2000). Alternatively, it is a poleward boundary intensification excited by magnetotail reconnection (see AL excursion and PCN rise at this time).

Equatorward of these arcs the oval section at 17.9 MLT is occupied by a wide band of diffuse auroral precipitation and a moderate sunward-directed convection (within 57$70^{\circ}$ MLAT). A correspondingly weak FAC configuration is indicated by the dashed vertical arrows.

Figure 8 shows $X$ component deflections from three stations in the IMAGE chain: NAL (75.2 $2^{\circ}$ MLAT), MAS (66.2 $2^{\circ}$ MLAT) and NUR (56.9 ${ }^{\circ}$ MLAT). From crossings of the auroral oval and PC boundary at dusk by DMSP F13 at 13:26, 15:08 and 16:48 UT (see below) we find that in this interval the polar cap boundary is located at $72-73^{\circ}$ MLAT. This means that station NAL is located well within the polar cap. The oval is spanning the range 58/59-72/73 ${ }^{\circ}$ MLAT.
This means that station MAS is in the oval and that station NUR is located near the oval equatorward boundary.

Noteworthy are the two major transient electrojet activations at 14:20 and 15:46 UT and a less intense event at 13:15 UT. The latter event is close to the first satellite pass. These events are characterized by abrupt increases in the EEJ (positive $X$ deflection at NUR; green trace), in the WEJ (negative $X$ deflection at MAS; red trace) and a polar cap convection bay (negative $X$ deflection at NAL; black trace). The bipolar (positive-to-negative) deflection detected at MAS at 14:20 UT is referred to in the literature as a "transition bay" (Rostoker, 1966). This kind of deflection occurs when the station is first in the regime of the EEJ and later in the WEJ sector associated with the westward (or equatorward) expansion of the WEJ and the Harang reversal boundary. Referring back to Fig. 3 we can see that the transient electrojet events at 14:20 and 15:45 UT are accompanied by PCN rises from $\sim 2.5$ to $3.5 \mathrm{mV} \mathrm{m}^{-1}$.

Figure 9 shows $X$ component deflections from six IMAGE chain stations in the interval 14:00-16:00 UT, centered around the pass across the oval at dusk by DMSP F13 during 
F13 18 Aug 2003

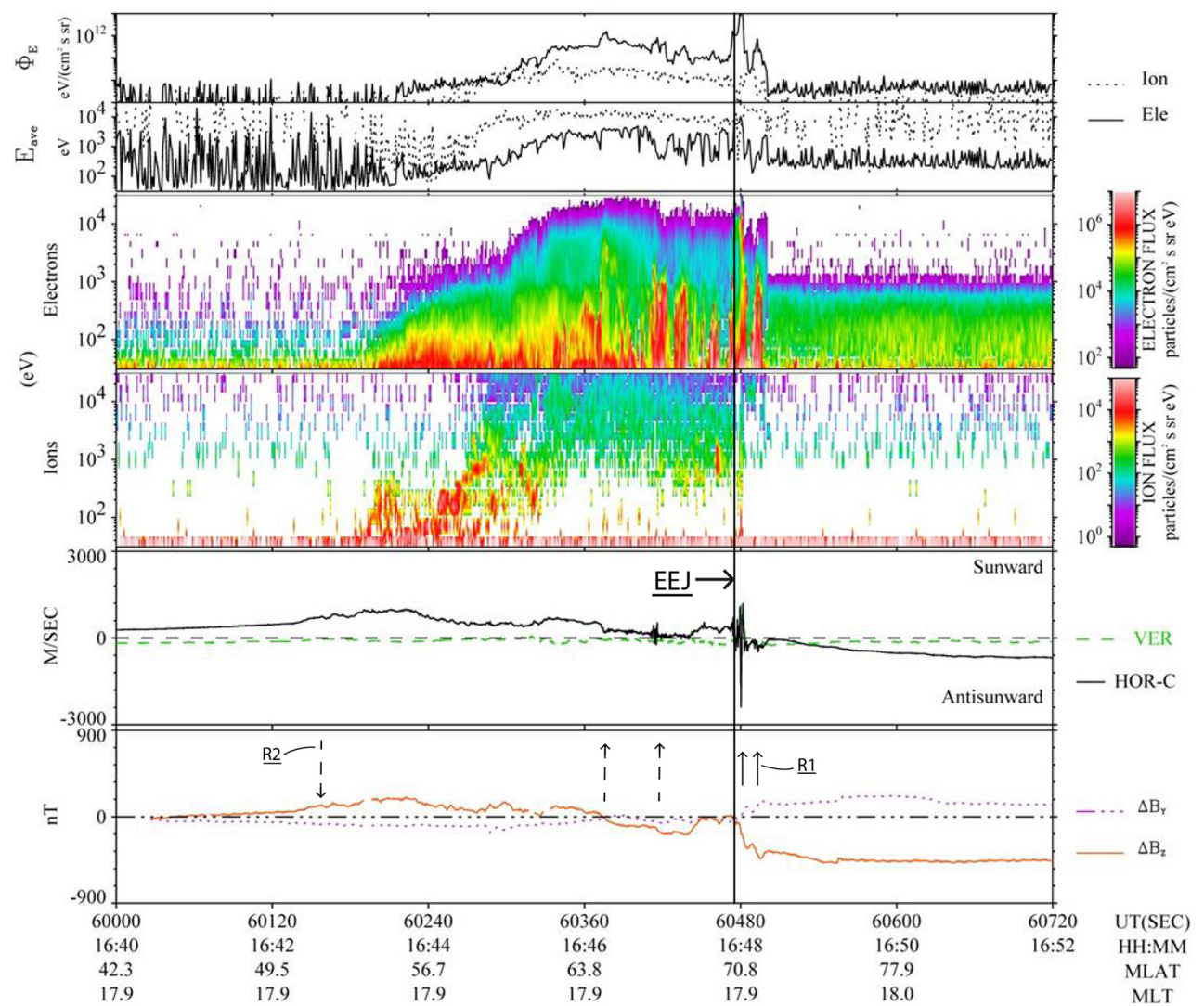

Fig. 7. DMSP F13 data for the dusk-side oval traversal from south to north during interval 16:40-16:52 UT. Same format as in Fig. 6.

15:04-15:09 UT. The stations span the latitude range from 75.2 (NAL) to $63.5^{\circ}$ MLAT (PEL). The trace from station LOZ (64. $2^{\circ}$ MLAT) in the bottom panel is included because LOZ is located slightly to the east of the other stations (in Kola Peninsula, Russia). The two major WEJ events at 14:20 and 15:45 UT are easily identified. Referring back to Fig. 4 we note the association with major AL events and corresponding SYM-H dips at these times. The 14:20 UT event is characterized by a WEJ expansion from the eastern side of the IMAGE chain. This WEJ activity is attributed to the westward expansion of the M-I current system called the SCW (see schematic illustration in Fig. 1).

This activity is preceded by a positive deflection (EEJ intensification) at stations SOR, MAS, PEL and LOZ in the interval 14:15-14:20 UT. The WEJ expansion event is followed by an interval characterized by auroral streamers propagating equatorward from the high-latitude branch of the aurora, centered at $\sim 71^{\circ}$ MLAT (see satellite data above), during 14:25-15:10 UT. This is an interval of partial AL recovery (AL within -500 to $-700 \mathrm{nT}$ ), possibly dominated by BBFs.

We note the positive $X$ deflections (EEJ activity) at stations LOZ, PEL, MAS and SOR in the interval 14:4514:55 UT, after the eastward retreat of the short-lived WEJ expansion event (also affecting stations PEL and LOZ). The negative deflections at stations PEL and SOR in this interval are not so strong as the positive deflections in the EEJ signature. The latter EEJ events are expanding westward in the 18:00-17:00 MLT sector (compare LOZ and PEL traces within 14:43-14:45 UT) and poleward within $63-67^{\circ}$ MLAT (PEL, MAS and SOR). This evolution is consistent with the process of R2 FAC excitation and coupling to Harang regionsouth associated with plasma intrusion and flow braking, as sketched in Fig. 1.

The streamer activity detected at stations BJN and SOR (within 67-71 ${ }^{\circ}$ MLAT) during 15:06-15:07 UT occurred in the vicinity of the DMSP F13 trajectory during its crossing of the Harang reversal boundary from south to north along the 17.5 MLT meridian. This ground-satellite conjunction gives us a chance to identify the particle precipitationFAC-ion drift signatures of these streamer events (see F13 data description above). The satellite pass (15:05-15:10 UT) occurred in an interval of very dynamic behavior of the HRB (north-south motions within the $63-67^{\circ}$ MLAT range), as inferred from the ground magnetic data during 14:4515:20 UT. This latitude range roughly corresponds to the regime located between HR-S and HR-N in Fig. 6. 


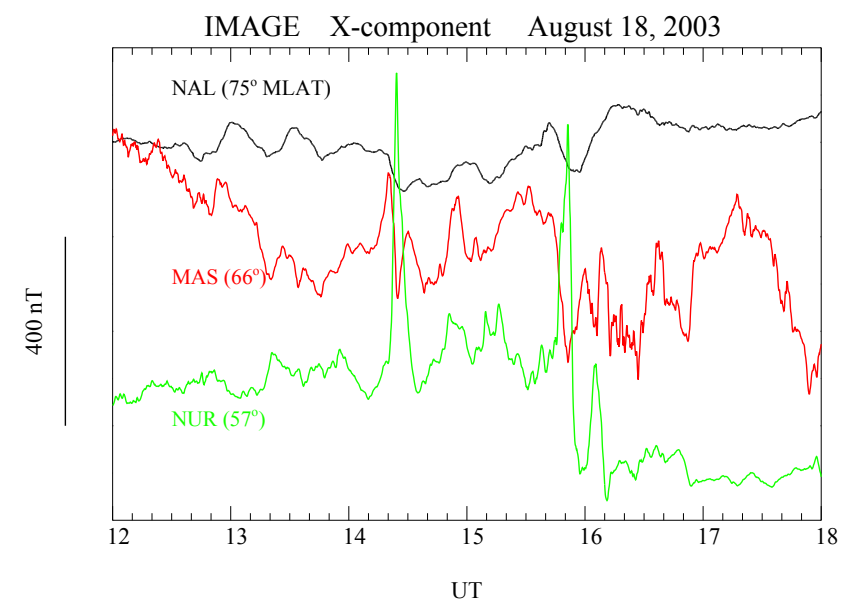

Fig. 8. $X$ component (north) deflections at three IMAGE stations during the interval 12:00-18:00 UT. The stations are NAL (75.2 ${ }^{\circ}$ MLAT; black), MAS $\left(66.2^{\circ}\right.$ MLAT; red), and NUR $\left(56.9^{\circ}\right.$ MLAT (green).

One may note the few-minute delay of the $X$ component signature of the last streamer event (15:10-15:20 UT) at station LOZ. This is consistent with the southeastward propagation of the streamers along the HRB at dusk (see geometry indicated in Fig. 1). The streamer signature is observed within the field of view of these stations (spanning the latitude range 71 to $63^{\circ}$ MLAT) during a 10 min-long interval (15:10-15:20 UT). The properties of the streamer deflections, i.e., their amplitude and temporal scale, as well as the propagation pattern (equatorward from PBIs in the highlatitude auroral branch), are all consistent with an interpretation in terms of plasma sheet flow bursts (BBFs) (see Cao et al., 2010, their Fig. 4).

The PC convection monitored at station NAL indicates the presence of enhanced antisunward convection in the intervals 14:20-14:50 and 15:05-15:10 UT. This observation is also consistent with the PCN index shown in Fig. 4.

Figure 10 shows magnetic field and high-energy electron fluxes during the interval 05:00-17:00 UT. GOES-10 is in geostationary orbit $\left(6.6 R_{\mathrm{E}}\right)$. During the interval shown (05:00 to 17:00 UT) GOES-10 moved with the Earth from the evening sector (20:00 MLT; 05:00 UT) through midnight (24:00 MLT; 09:00 UT) to the prenoon sector (08:00 MLT; 17:00 UT). The two subintervals (I) 05:00-12:00 (20:0003:00 MLT) and (II) 12:00-16:00 UT (03:00-07:00 MLT) are characterized by two different event categories. Interval I shows cycles of field line stretching $\left(B_{z}\right.$ decrease/ $B_{x}$ increase)-dipolarization ( $B_{z}$ increase $/ B_{x}$ decrease) events, while interval II shows a sequence of shorter events each characterized by $B_{z}$ increase, $B_{x}$ decrease and $B_{y}$ increase.

The field stretching-dipolarization events in interval I are accompanied by corresponding events of decreaseincrease in the local high-energy $(\mathrm{MeV})$ electron fluxes at geosynchronous altitude. The magnetic perturbation events

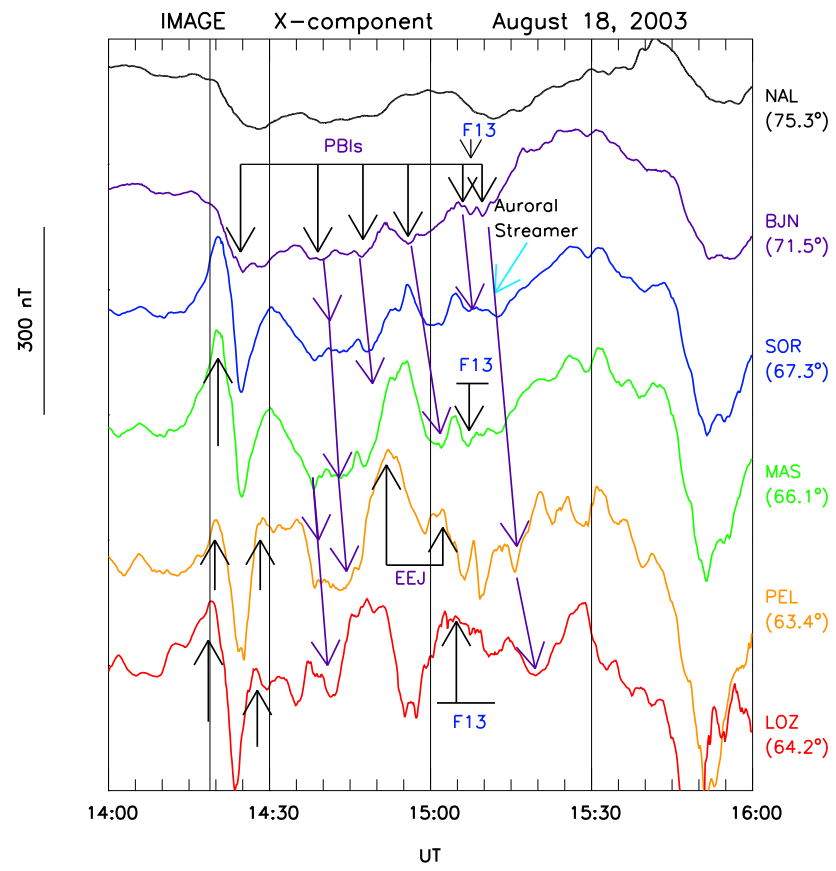

Fig. 9. $X$ component deflections at six IMAGE stations during the interval 14:00-16:00 UT. Panels from top to bottom show $X$ component traces from stations NAL $\left(75.2^{\circ}\right.$ MLAT), BJN (71.4 $4^{\circ}$ MLAT), SOR (67.3 ${ }^{\circ}$ MLAT), MAS (66.2 MLAT), PEL (63.5 MLAT), and LOZ $\left(64.2^{\circ}\right.$ MLAT). Positive deflections in Harang region-south and negative deflections in Harang region-north are marked by arrows. Tilted arrowed lines are used to indicate equatorward-moving streamer events in HR-N. The time when DMSP F13 passed across the oval at dusk in the interval 15:04-15:09 UT is also marked by arrows.

in interval II are accompanied by energetic particle flux dropouts.

We note that major GOES-10 dipolarization events in interval I (see $B_{z}$ maxima centered at 07:30, 09:15, 10:00, and 11:30 UT) are accompanied by corresponding peaks in the PCN index (see bottom panel). $B_{z}$ minima $(\sim 10 \mathrm{nT})$ at 06:25, 08:45 and 11:00 UT are followed by field dipolarizations and PCN increases. These are also times of AL activities. However, the field dipolarization at 06:25 UT lead to only a short-lived AL excursion and a modest PCN increase. The AL event (WEJ activation) at 06:25 UT is more clearly manifest in Alaska magnetograms (e.g., at auroral oval station Poker Flat; 19:00 MLT; see below) than in the present AL index. The AL events (WEJ activations) initiated at 07:00, 08:45 and 11:00 UT are major onsets $(\mathrm{AL}=-800$ to $-1600 \mathrm{nT}$ ) followed by long-lived (persistent) AL activity. In these cases we may distinguish between (i) an initial transient phase and (ii) a persistent phase of the AL-PCN activity. This type of 2-phase AL-PCN activity is most clearly manifest in the interval 04:00-08:10 UT (see also Fig. 3).

In interval II (12:00-17:00 UT) we note that the major GOES-10 magnetic field-particle flux events (exemplified 


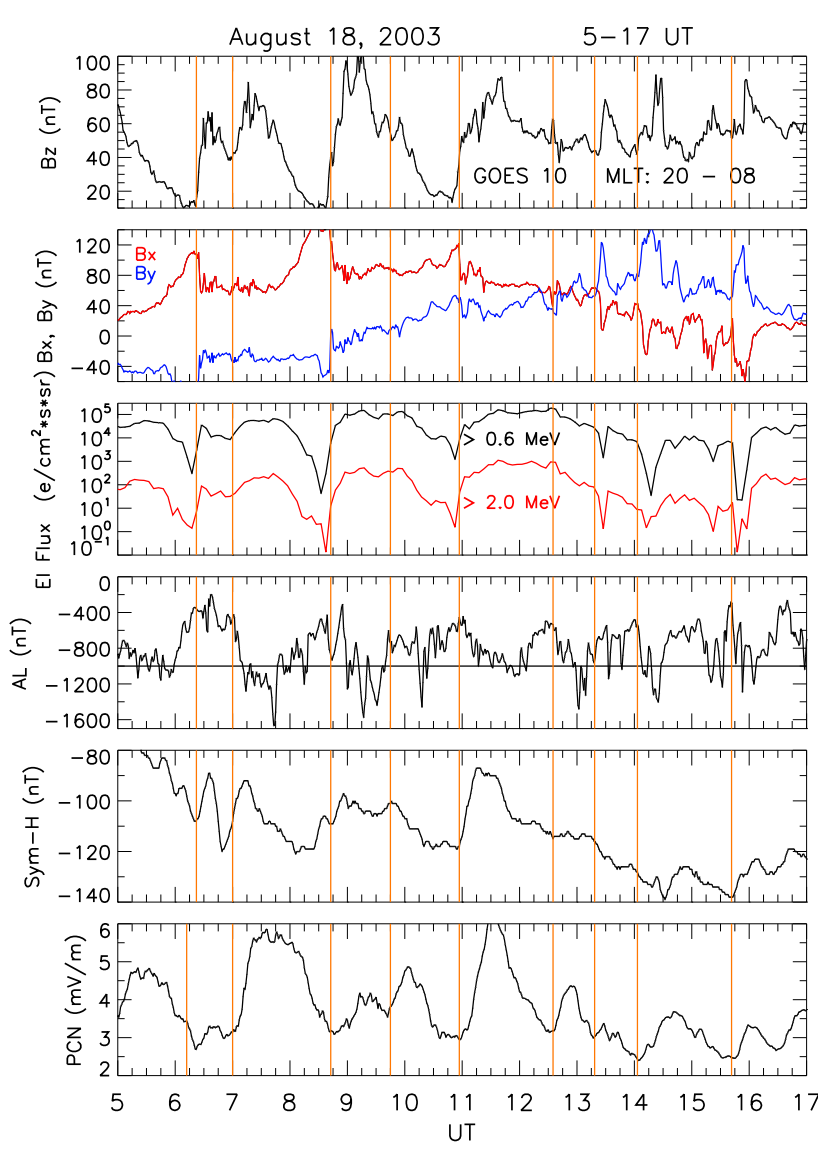

Fig. 10. GOES-10 field and plasma data (first three panels) and magnetic indices AL, SYM-H and PCN for the interval 05:0017:00 UT. Panels 1 and 2 show GOES magnetic field components $B_{z}$ (black in top panel), $B_{x}$ (red), $B_{y}$ (blue) at geosynchronous altitude, when the spacecraft moved from evening (20:00 MLT; 05:00 UT) through midnight (24:00 MLT; 09:00 UT) to the morning sector (08:00 MLT; 17:00 UT). Panel three shows high-energy electron differential fluxes. Vertical guidelines illustrate the association between GOES-10 magnetic field events and PCN enhancements.

by the 14:10-14:20 and 15:45 UT activities) correspond to a distinct activity in Harang region-south recorded at dusk (see the impulsive events in Fig. 8) and associated PCN enhancements. In this interval the background field is $B_{x}>$ $0 / B_{y}>0 / B_{z}>0$ as expected for the dawn sector (above the equatorial plane). The M-I coupling associated with the $B_{x}<0 / B_{y}>0$ events in the interval 13:00-16:00 UT will later be discussed in terms of the activation of substorm current systems (Fig. 1).

We now return to the interval I activity and focus on the specific $B_{z}-\mathrm{SYM}-\mathrm{H}-\mathrm{PCN}$ event initiated at $\sim 11: 00 \mathrm{UT}$. The steep $B_{z}$ increase / $B_{x}$ decrease (dipolarization) at 11:00 UT is followed by a SYM-H partial recovery from 11:0011:15 UT (the largest recovery during the whole interval shown). The PCN rise starts at 11:05 UT and continues until 11:40 UT. In this case the PCN value reached the highest value $\left(6 \mathrm{mV} \mathrm{m}^{-1}\right)$ during the whole day at $\sim 11: 40 \mathrm{UT}$. This event occurred in association with a magnetic field dipolarization after a field line stretching interval, as observed by GOES-10. Interestingly, this event can also be connected with a transient signature in the interplanetary CME magnetic field leading to an abrupt $E_{\mathrm{KL}}$ increase from 7 to $8.5 \mathrm{mV} \mathrm{m}^{-1}$ at 10:00 UT (ACE time; see Fig. 2). Therefore it is likely that the dayside source of polar cap convection contributes to this PCN event, in addition to the nightside source (see AL index). Against this background we wanted to investigate the ground magnetic response in the high-latitude postnoon sector during the interval 11:00-12:00 UT. This information is available in the data from the IMAGE Svalbard chain of magnetometer stations covering the latitude range 71-75 ${ }^{\circ}$ MLAT. The interval 11:00-12:00 UT represents the $\sim$ 14:30-15:30 MLT sector at these stations.

Figure 11 shows $X$ component magnetograms from IMAGE chain stations on Svalbard (NAL, HOR and BJN: 75, 74 and $71^{\circ}$ MLAT, respectively) and mainland (Norway) station SOR $\left(67^{\circ} \mathrm{MLAT}\right)$ for the interval 10:00-15:00 UT. Deflections at the Svalbard chain in the interval 10:57-12:00 UT $(\sim 14: 30-15: 30$ MLT sector) show the response in the postnoon sector to an enhancement of the dayside source of polar cap convection (see $E_{\mathrm{KL}}$ enhancement based on ACE data; marked by a vertical guideline at 10:00 UT in Fig. 2). The magnetic activity in the interval 10:57-12:00 UT reflects a substructure of the dayside convection response (three consecutive convection events) which is seen as a single PCN peak reaching $6 \mathrm{mV} \mathrm{m}^{-1}$ at $\sim 11: 40 \mathrm{UT}$. The first event in the sequence (from 10:57 UT onwards) represents a pulse of flux erosion driven by the $E_{\mathrm{KL}}$ enhancement. The polewardpropagating convection events inferred from the BJN-HORNAL traces can be identified as pulsed ionospheric flows (PIFs; see e.g. Provan et al., 2002) appearing on old open field lines in the mantle/polar rain regime (what we call flow channel FC 2; see below). These events can be interpreted as flux transfer event (FTE) flux tubes moving along the polar cap boundary in the postnoon sector (see e.g. Southwood, 1987). During their tailward motion these flux tubes are expected to transfer momentum to the ionosphere in a 20 min interval after reconnection took place at the dayside magnetopause (in the interval 10:57-11:17 UT after the first reconnection pulse). The first $\sim 10 \mathrm{~min}$ interval is characterized by newly open field lines (flow channel FC 1) and poleward-moving auroral forms (see Sandholt and Farrugia, 2007), while the interval from $\sim 10$ to $20 \mathrm{~min}$ after reconnection (old open field lines) occurs in the regime of mantle/polar rain precipitation and a channel of enhanced antisunward flow (FC 2) adjacent to the polar cap boundary, particularly in the winter hemisphere where a large conductivity gradient is present (Sandholt and Farrugia, 2009).

Thus, the negative/positive $X$ deflections at 10:57 UT $(\sim 14: 30$ MLT), marked by a dashed vertical line in the figure, are signatures of the dayside convection response to enhanced interplanetary driving as represented by the 


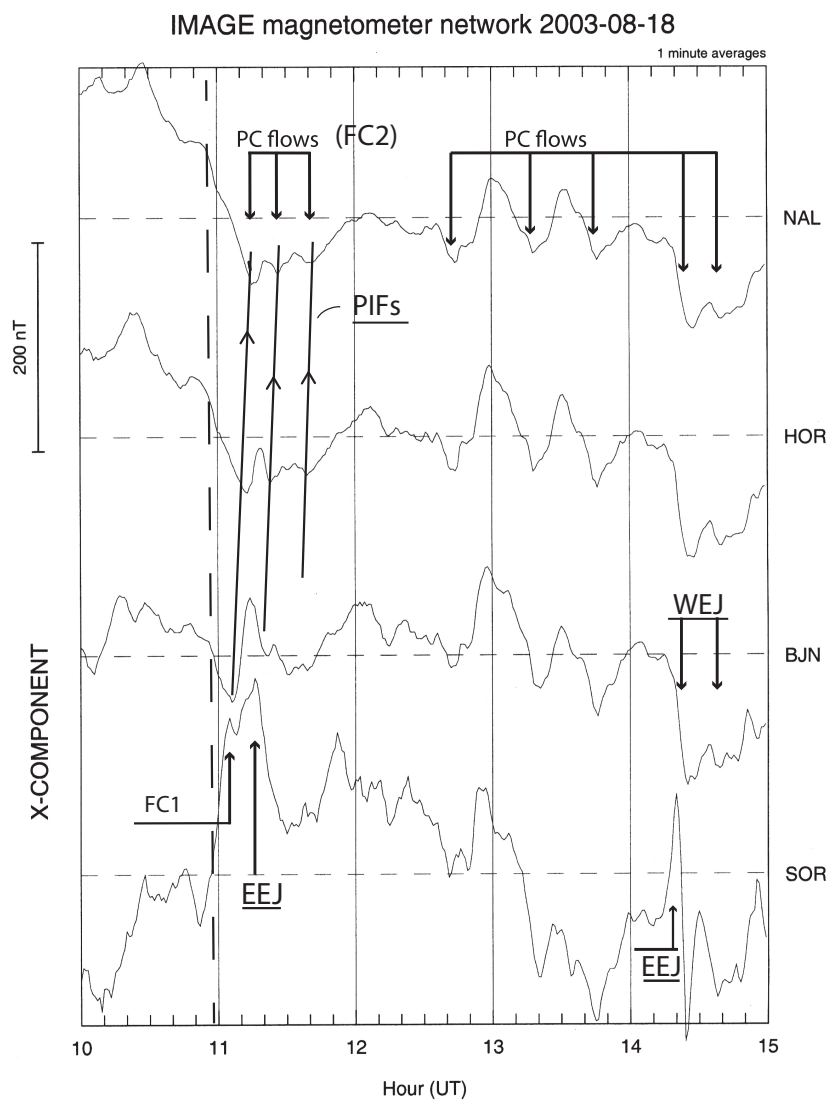

Fig. 11. $X$ component magnetograms from IMAGE chain stations on Svalbard (NAL, HOR and BJN: 75,74 and $71^{\circ}$ MLAT, respectively) and mainland station SOR $\left(67^{\circ}\right.$ MLAT) for the interval 10:00-15:00 UT. Marked by arrows are signatures of polewardpropagating pulsed ionospheric flows (PIFs) in the postnoon sector within 11:00-12:00 UT ( 14:30-15:30 MLT) and polar cap (PC) flow events (top panel) in the interval 12:30-15:00 UT $(\sim 16: 00$ 18:30 MLT). Events of positive $X$ deflection at SOR, associated with newly open field lines (FC 1) and return flows centered at lower latitudes (EEJ), are marked in the bottom trace (SOR).

reconnection electric field (see $E_{\mathrm{KL}}$ parameter in Fig. 2). The positive $X$ response at SOR is consistent with enhanced northwestward convection in the regime close to the ionospheric projection of the merging line, which is expected to be longitudinally expanded in this case of magnetopause erosion event (see e.g. Crooker et al., 1991). For documentations of associations between auroral, magnetic and convection signatures of pulsed magnetopause reconnection in the postnoon sector we refer to Sandholt et al. (1986), Sandholt and Farrugia (2007) and Sandholt et al. (2010).

Summarizing the observations most relevant to the present case (PCN event between 11:00 and 12:00 UT), we may list the following sequence of events: (i) abrupt $E_{\mathrm{KL}}$ enhancement at 10:00 UT (ACE time), (ii) three pulses of enhanced dayside convection in the interval 10:57-11:40 UT, (iii) continuous PCN increase from 3 to $6 \mathrm{mV} \mathrm{m}^{-1}$ between 11:05 and 11:40 UT, followed by decrease, (iv) magnetic field dipolarizations at GOES-10 (located within 02:00-03:00 MLT) $\left(B_{z}\right.$ increase from 20 to $50 \mathrm{nT}$ during 10:52-11:00 UT and from 50 to $85 \mathrm{nT}$ during 11:00-11:45 UT), and (v) AL decrease from -400 to $-1000 \mathrm{nT}$ during 11:00-12:00 UT.

From these observations we conclude that both the dayside and nightside sources of polar cap convection were active contributors to the PCN event in the interval between 11:00 and 12:00 UT.

Later in the interval shown (12:30-15:00 UT) we have marked in the NAL trace in Fig. 11 polar cap convection events, i.e., antisunward polar cap flow events recorded in the 16:00-18:30 MLT sector (see correlation with PCN peaks). In this MLT regime station NAL becomes increasingly more sensitive to the nightside source of polar cap convection with time. The 14:20 UT event is one of the major substorm (WEJ) expansion events reported above. At this time station SOR is initially in the EEJ regime, but later the WEJ expanded beyond this station, causing the transition bay (positive-negative $X$ deflection) we discussed earlier. From the DMSP F13 crossing of the polar cap boundary at $73^{\circ}$ MLAT (16.5 MLT) at 13:26 UT (Fig. 5) we infer that station NAL $\left(75^{\circ} \mathrm{MLAT}\right)$ is located well inside the polar cap around this time.

We now present observations of substorm activity in interval I (05:00-12:00 UT) representing the ionospheric part of M-I coupling at MLTs closer to midnight. This is the westward electrojet in the Bostrøm type I current system (substorm current wedge; see Fig. 1).

Figure 12 shows the $H$ component traces from five Alaska chain stations in the interval 06:00-12:00 UT which cover the MLT sector 19:00-01:00 MLT. These stations are spanning the latitude regime $63.6-68.7^{\circ}$ MLAT. These traces provide a good supplement to the AL index concerning the WEJ evolution in this particular interval. Pseudo-breakups at 06:25, 08:40 and 10:55 UT are marked by vertical guidelines. We note the good correlation between GOES-10 dipolarizations and major onsets (07:02, 09:00 and 11:06 UT) in the interval 09:00-12:00 UT (21:00-01:00 MLT). During the 09:0009:50 and 11:00-12:00 UT substorms we do see a detailed correlation between GOES-10 $B_{z}$ enhancements and WEJ intensifications. These events show the signature of doubleonset substorms; i.e., a pseudo-breakup is followed by a major onset (see e.g. Nakamura et al., 1999). Most major excursions reached beyond $-1000 \mathrm{nT}$. Each major WEJ enhancement (the transients at 07:02, 09:00, and 11:06 UT), spanning a wide latitude range $\left(63.8-68.7^{\circ} \mathrm{MLAT}\right)$, is followed by a longer interval of persistent WEJ activity.

In the Discussion section we shall place these observations in the context of M-I coupling processes with current systems as sketched in Fig. 1. Thus, the two categories of GOES perturbation events observed in intervals I (midnight sector) and II (dawn sector) will be attributed to the activation (intensification) of the Bostrøm type I (SCW centered near midnight) and II (centered at dusk and dawn) current 


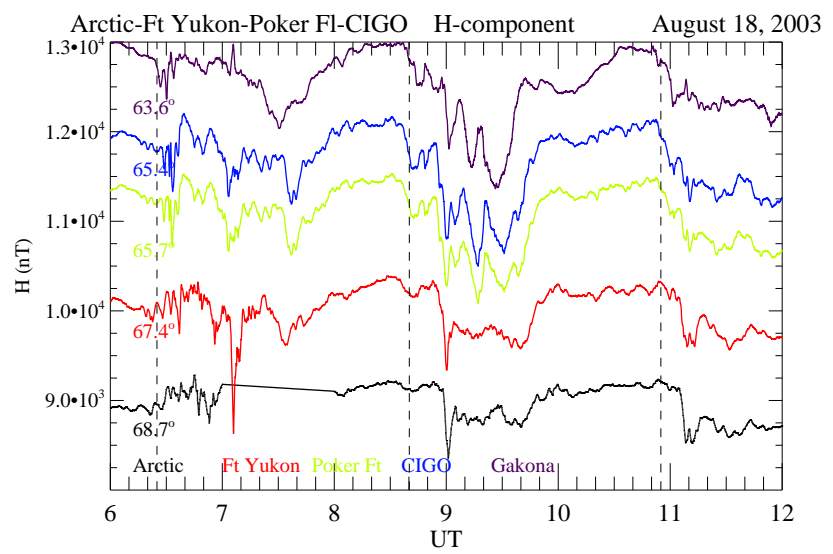

Fig. 12. Panels from top to bottom show $H$ (horizontal) component traces from stations in Alaska (increasing latitude from top to bottom): Gakona $\left(63.6^{\circ}\right.$ MLAT), CIGO $\left(65.4^{\circ}\right)$, Poker Flat $\left(65.4^{\circ}\right)$, Ft. Yukon $\left(67.4^{\circ}\right)$, and Arctic Village $\left(68.7^{\circ}\right)$ for the interval 06:00 12:00 UT. This interval corresponds to the 19:00-01:00 MLT sector. Pseudo-breakups are marked by vertical dashed lines.

systems, respectively. Related to this we also point out the association between the $B_{x}<0 / B_{y}>0$ events and the highenergy particle decreases in the interval 13:00-16:00 UT (see Discussion).

\section{Discussion}

The background for this study is related to the unsolved questions that exist on the spatial-temporal evolution of the electrodynamic coupling between the plasma sheet-lobe-ring current system and the ionosphere during substorms. According to Akasofu (2013) "we are still at an early stage of understanding auroral/magnetospheric substorms". One of the unsolved questions which we explore is related to the activation of the different elements of the composite pattern of substorm currents (M-I coupling) during the expansion phase of storm-time repetitive substorms. Thus, essential to us here is the temporal-spatial evolution of $\mathrm{M}-\mathrm{I}$ coupling in different latitude-longitude regimes, including the southern and northern sections of the auroral oval (at night and at dusk/dawn) and the polar cap during events initiated by plasma sheet current disruptions-magnetic field dipolarizations. Taking advantage of two different groundsatellite conjunctions in two separate intervals (05:00-12:00 and 13:00-17:00 UT), we investigate the roles of different branches of the substorm current system, i.e., (i) plasma sheet-R1-FAC-WEJ coupling (Bostrøm type I system centered near midnight), (ii) partial ring current-R2-FAC-EEJ coupling at dawn/dusk (Bostrøm type II system with signatures in Harang region-south), and (iii) $\mathrm{M}-\mathrm{I}$ coupling related to earthward-moving flux tubes/plasma flow events in two stages of their evolution: (a) a Bostrøm type I system associated with BBFs/streamers, with manifestations in Harang region-north, and (b) excitation of a Bostrøm type II system with dynamo action in the braking phase of flows/flux tubes at the plasma sheet-ring current boundary, with manifestations in Harang region-south (Fig. 1).

On the topic of auroral streamer activity, a central feature of our observations in Harang region-north at dusk, Haerendel (2011) stated: "In the case of auroral streamers we have a deplorable lack of electromagnetic data on the arcs and flow channels". Our discussion is relevant to substorms in general and applicable in particular to the specific substorm activity appearing during long intervals of continuously strong solar wind forcing, i.e., when major storms are in progress. Central to our approach is the combination of observations at dusk and at midnight MLTs. By this approach we aim at increasing our understanding of the dynamic $\mathrm{M}-\mathrm{I}$ coupling represented by the evolution of the classical current systems (Bostrøm types I and II) during the repetitive substorm activity which is driven by highly geoeffective interplanetary CMEs.

Two distinct stages of M-I coupling in the substorm expansion phase and corresponding activity levels are identified on the basis of our data sets. Phase 1 (the initial transient phase) is characterized by (i) a 10-20 min-long magnetic field dipolarization process in the near-Earth plasma sheet with typical dipolarization rate $\Delta B_{z} / \Delta t=50 \mathrm{nT} / 10 \mathrm{~min}$ $\approx 10^{-10} \mathrm{~V} \mathrm{~m}^{-2}$, (ii) transient enhancements of the WEJ within a wide latitude regime (63-69 MLAT) in the midnight sector (Alaska chain data in Fig. 12), (iii) corresponding impulsive electrojet intensifications on both sides of the Harang reversal at dusk (IMAGE chain in SvalbardScandinavia-Finland-Russia), and (iv) a 10-20 min-long monotonic rise in the PCN index.

Phase 2 (the persistent phase) is characterized by (i) nearEarth $B_{z}$ fluctuations and/or relatively high $B_{z}$ values before the field-stretching phase sets in, (ii) a series of westward electrojet activations near midnight and (iii) corresponding electrojet activity on both sides of the Harang reversal at dusk, and (iv) a persistent high or slowly decreasing PCN level. The WEJ activity in Harang region-north shows a series of equatorward-propagating $X$ component deflections and associated auroral streamer precipitation and FAC structure as documented in our ground (IMAGE chain)-satellite (DMSP F13) conjunction studies.

On this background we found it appropriate to apply the terminology previously used by Siscoe et al. (2011) to describe M-I coupling triggered by north-to-south transitions of the IMF, namely, an initial transient phase and a persistent phase.

The character of the initial transient phase (field dipolarization and associated impulsive electrojet events at midnight (Fig. 12) and dusk (Fig. 8)) indicates that inductive electric fields $\left(E_{\mathrm{PS}}\right.$ (inductive)) can play an important role in this phase. This is supported by the following reasoning. An expression for the local value of the dawn-dusk component of $E_{\mathrm{PS}}$ (inductive) may be derived from Maxwell-Faraday's 
law: $E_{\mathrm{PS}}$ (inductive) $=\left(\Delta B_{z} / \Delta t\right) \cdot L_{x}$, where $L_{x}$ is the radial dimension (along the $x$ axis) of the $\mathrm{CD} /$ dipolarization process.

Then we may derive the corresponding formula for the cross-polar-cap potential $(\mathrm{CPCP}) . \mathrm{CPCP}=k E_{\mathrm{PS}} \cdot L_{X} \cdot L_{Y}$, where the magnetosphere-ionosphere potential transmission factor $k=0.1-0.2$ (Gordeev et al., 2011). $L_{y}$ is the dawn-dusk dimension of the $\mathrm{CD} /$ dipolarization process. Here we use the following estimates: $\Delta B_{z} / \Delta t(\mathrm{GOES}-10) \approx 50 \mathrm{nT} / 10 \mathrm{~min} \approx 10^{-10} \mathrm{~V} \mathrm{~m}^{-2}$;

$L_{x} \approx 10 R_{\mathrm{E}} ; L_{Y} \approx 20 R_{\mathrm{E}}$. $E_{\mathrm{PS}}$ (ind.) $\sim 5 \mathrm{mV} \mathrm{m}^{-1}$. From this we get for the CPCP enhancement $\sim 50-100 \mathrm{kV}$. $L_{x}$ in the magnetotail corresponds (maps) to the latitudinal width of the WEJ at midnight (indicated in Fig. 12).

The corresponding value for the enhancement of the $\mathrm{PCN}$ index is $\triangle \mathrm{PCN}=$ const. $\cdot E_{\mathrm{PS}}=2-4 \mathrm{mV} \mathrm{m}^{-1}$. This relation for PCN is based on combined observations of PCN and CPCP enhancements documented by Sandholt et al. (2012), as summarized in the empirical relation $\triangle \mathrm{CPCP}$ $(\mathrm{V}) \sim 5 \cdot \Delta \mathrm{PCN}\left(\mathrm{mV} \mathrm{m}^{-1}\right) \cdot L_{\mathrm{PC}}(\mathrm{km}) . L_{\mathrm{PC}}$ is the cross-polar cap distance. The derived value for a typical PCN enhancement in the transient phase fits well with the observations in our case.

According to our estimates, the PCN enhancement from 3 to $6 \mathrm{mV} \mathrm{m}^{-1}$ during the interval 11:00-11:40 UT consists of a major contribution from the nightside source $(\triangle \mathrm{PCN}$ night $\sim 2.5 \mathrm{mV} \mathrm{m}^{-1}$ ) and a smaller contribution from the dayside source $\left(\triangle \mathrm{PCN}\right.$ day $\sim 0.6 \mathrm{mV} \mathrm{m}^{-1}$; based on the relation $\triangle \mathrm{PCN}$ day $/ \mathrm{PCN}$ day $=\Delta E_{\mathrm{KL}} / E_{\mathrm{KL}}$ ). The corresponding CPCP-day ( $E_{\mathrm{KL}}$ enhancement) and CPCP-night (substorm) enhancements are then $\sim 20 \mathrm{kV}$ and $50-100 \mathrm{kV}$, respectively, in this transient phase. Here we assume that the dayside source has not reached the level of saturation.

Related to the above estimates we note that the CPCP value $\left(E_{\mathrm{PC}} \times L_{\mathrm{PC}}\right)$ derived from the DMSP F13 potential curve (difference between potential maximum and minimum along the track; not shown) during the polar cap crossing in the interval 13:25-13:37 UT (Fig. 5) is $167 \mathrm{kV}$ $\left(\sim 35 \mathrm{mV} \mathrm{m}^{-1} \times 4700 \mathrm{~km}\right)$. This value is consistent with CPCP-day and CPCP-night contributions of $\sim 115$ and $\sim 50 \mathrm{kV}$, respectively.

In contrast to the transient phase, the persistent phase, which is characterized by a PCN plateau or a slowly decreasing PCN, is most likely dominated by potential electric fields associated with the integrated effect of $V_{x}-B_{z}$ events (BBFs/dipolarization fronts) in the mid-tail plasma sheet: $E_{\mathrm{PS}}$ (potential) $\left(=V_{x} \cdot B_{z}\right)$. Our distinction between the roles of potential and inductive electric fields in the magnetotail during the substorm process is in line with the study of $\mathrm{Pu}$ dovkin et al. (1991). However, based on our observations of the association between near-Earth dipolarization and PCN rise in the transient phase we reserve a larger role for inductive electric fields in the excitation of polar cap convection in this particular phase.

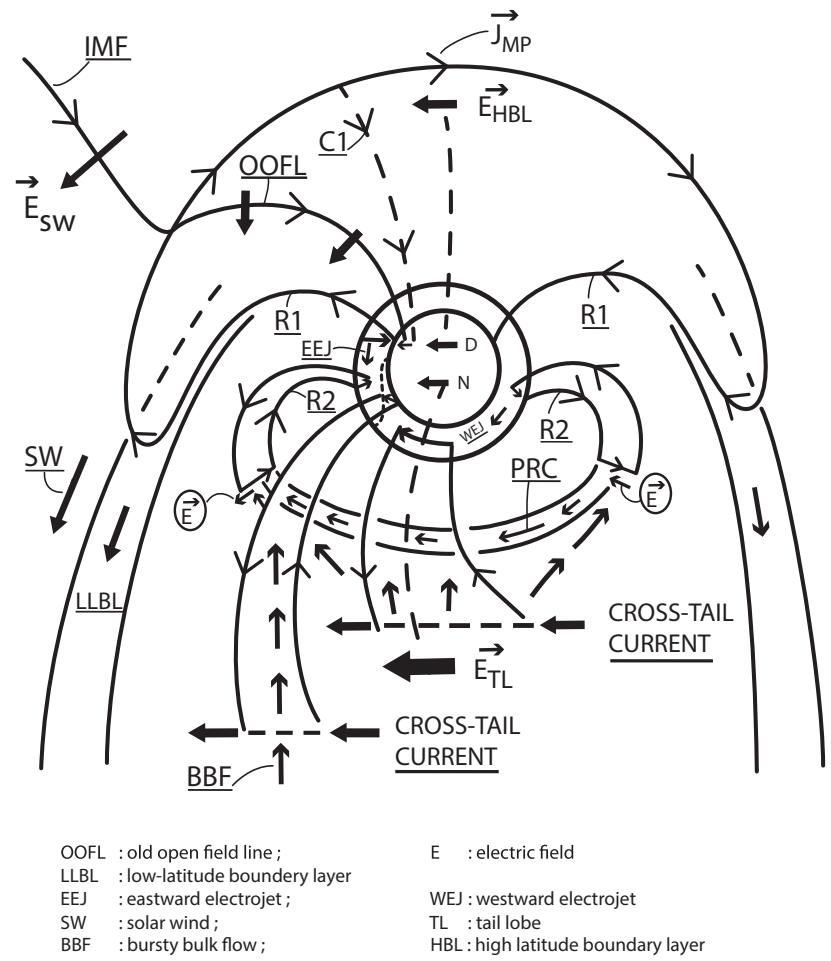

Fig. 13. Schematic illustration of Northern Hemisphere current systems relating to the dayside and nightside sources of polar cap convection as marked by two dawn-to-dusk-directed $\boldsymbol{E}$ fields ( $D$ and $N$ ) in the polar cap. The dayside source consists of dynamo processes $(\boldsymbol{E} \cdot \boldsymbol{J}<0)$ in magnetospheric boundary layers (BLs) at high (HBL) and low (LLBL) latitudes. $\boldsymbol{E}$-field coupling from the solar wind $\left(\boldsymbol{E}_{\mathrm{SW}}\right)$ (along old open field lines) to the polar cap in the postnoon sector is illustrated for a southwest-directed IMF $\left(B_{z}<0\right.$; $\left.B_{y}<0\right)$. Dayside R1 FACs connected to the low-latitude boundary layer (LLBL) and the magnetopause current flowing over the top of the magnetosphere $\left(J_{\mathrm{MP}}\right)$ are shown. The substorm current systems are reproduced from Fig. 1. The auroral oval is represented by two concentric circles. The Harang reversal boundary is marked by a dashed curved line connecting the poleward and equatorward oval boundaries at dusk-premidnight. $\boldsymbol{E}$-field coupling from the tail lobe $\left(\boldsymbol{E}_{\mathrm{TL}}\right)$ to the nightside polar cap ionosphere $(N)$ is indicated.

Figure 13 illustrates our effort at integrating the information extracted from the different data sets into a consistent picture of the substorms process in the context of the basic elements of solar wind-magnetosphere-ionosphere coupling applicable to the strong forcing case (interplanetary CME) we study. The dayside and nightside current systems responsible for the two-source nature of polar cap convection are marked in this schematic drawing (see two dawn-to-duskdirected $\boldsymbol{E}$ fields indicated by bold arrows in the PC). The dayside source is shown in the variant of negative IMF $B_{y}$ conditions (southwest-directed IMF) with $\boldsymbol{E}$-field coupling along old open magnetic field lines (OOFLs), giving rise to a prenoon versus postnoon convection asymmetry (see e.g. Heppner and Maynard, 1987), i.e., $\boldsymbol{E}$-field concentration in 
the postnoon sector via ionospheric Pedersen current closure of FACs marked R1-C1 (our FC 2 flow channel), as described by Sandholt and Farrugia (2009) and Sandholt et al. (2010). The ground magnetic signature of this dayside convection source is demonstrated in Fig. 11 above (see also discussion in relation to the presentation of this figure). The dayside source of polar cap convection is regulated by $E_{\mathrm{KL}}$ (Reiff et al., 1981; Kullen et al., 2010). According to Kullen et al. (2010) the summer PC index correlates particularly well with $E_{\mathrm{KL}}$. This is demonstrated in our case by the 11:00 UT event (see PCN increase during 11:00-11:40 UT), which includes a response to the abrupt $E_{\mathrm{KL}}$ increase detected by $\mathrm{ACE}$ at 10:00 UT (see Fig. 2). However, from the relation $\Delta \mathrm{PCN}$ day $/ \mathrm{PCN}$ day $=\Delta E_{\mathrm{KL}} / E_{\mathrm{KL}}$ (see Troshichev et al., 2000 ) we find (see $E_{\mathrm{KL}}$ enhancement from 7 to $8.5 \mathrm{mV} \mathrm{m}^{-1}$ at $\approx 10: 00$ UT in Fig. 2) that the contribution from $\triangle \mathrm{PCN}$ day is relatively minor $\left(\approx 0.6 \mathrm{mV} \mathrm{m}^{-1}\right)$ compared to the $\mathrm{PCN}$ night enhancement $\left(\approx 2.5 \mathrm{mV} \mathrm{m}^{-1}\right)$ in this case. By using IMAGE chain data which are more sensitive to the dayside convection source, we added information on the pulsed behavior of the dayside source (MP reconnection) which is not resolved in the PCN index (Fig. 11).

Our observations at dusk and midnight MLTs will be discussed within the framework of the schematic illustration in Fig. 13. A possible scenario for the type of repetitive substorms we study is a cycle involving (i) loading of magnetic flux in the tail lobes, (ii) plasma sheet thinning/stretching of the magnetotail field (see e.g. Baumjohann et al., 1992), and (iii) disruption of the cross-tail current and magnetic field dipolarization (see e.g. Jacquey and Sauvaud, 1992). This cycle is driven by continued magnetopause reconnection during the long intervals of southward-directed interplanetary magnetic field in interplanetary CMEs.

The nightside source of polar cap convection involves the basic elements of M-I coupling processes from different magnetotail regimes applicable to our case: (i) R2 coupling from flow channel (injection dynamo) at the outer edge of the partial ring current, at a radial distance of $\sim 6.6 R_{\mathrm{E}}$ (see GOES-10 data); (ii) R1 FAC coupling from largescale current disruptions in the near-tail region (within $\sim 6-$ $12 R_{\mathrm{E}}$ radial distance); and (iii) $\mathrm{R} 1$ coupling from smallerscale current disruptions in the mid-tail (earthward-moving dipolarization fronts/BBFs-plasma-depleted flux tubes possibly originating at the near-Earth neutral line beyond $X \sim$ $-20 R_{\mathrm{E}}$.

A central element in our interpretation is as follows: the decrease (disruption) of the CTC and the activation of the $\mathrm{SCW}$ in the near-Earth plasma sheet is accompanied by a dipolarization of the magnetic field, as documented in the GOES-10 data (see Fig. 10), giving rise to inductive magnetotail electric fields. At substorm onsets $B_{z}$ enhancements $\left(\Delta B_{z} / \Delta t \sim \Delta B_{x} / \Delta t \sim 10 \mathrm{nT} / 10 \mathrm{~min}\right)$ in the tail lobes $(X=$ $-17 R_{\mathrm{E}}$ ) have previously been observed to be accompanied by $\boldsymbol{E}$-field enhancements in the tail lobe ( $E_{\mathrm{TL}}$; see Sauvaud et al., 2012). This M-I coupling from the tail lobes to the polar cap ionosphere is schematically indicated in Fig. 13. The radial extent (outward expansion) of the dipolarization process (see our estimate of the parameter $L_{X}: \sim 5-10 R_{\mathrm{E}}$ ), corresponds to the latitudinal extent of the WEJ at midnight. The magnetic perturbation (and associated inductive electric field) in the tail lobes gives rise to polar cap convection enhancement (PCN night $\left.\propto E_{\mathrm{PS}} \cdot L_{x}\right)$. The longitudinal expansion of SCW (our $L_{Y}$ parameter), corresponding to the expansion of the WEJ into the 17:00-18:00 MLT sector, contributes to the CPCP enhancements in the transient phase of our cases $\left(\triangle \mathrm{CPCP} \propto E_{\mathrm{PS}} \cdot L_{Y}\right)$.

The subsequent persistent phase is characterized by a series of equatorward-propagating auroral streamers in Harang region-north and EEJ enhancements in Harang region-south. The latter is explained by a dynamo process $(\boldsymbol{E} \cdot \boldsymbol{J}<0)$ in the regime of braking of intruding plasma (the injection dynamo) and activation of a Bostrøm type II current system at dusk, as illustrated in the figure.

With reference to Fig. 13 we suggest the following SWM-I coupling processes in our case of repetitive substorm activity, based on the observations: (i) dayside and nightside sources of polar cap convection with ground stations in Svalbard being sensitive primarily to the dayside and nightside convection sources in the intervals before and after $\sim 12: 30$ UT $(\sim 16: 00 \mathrm{MLT})$, respectively, in our case; (ii) cycles of magnetic field stretching-dipolarization observed by GOES-10; (iii) current disruptions (CD)/magnetic field dipolarizations in the near-Earth magnetosphere (observed at geosynchronous altitude) with activations of the SCW involving R1 FAC coupling to the WEJ, leading to AL dips (and magnetic perturbations near midnight in Alaska); (iv) rapid longitudinal expansions of $\mathrm{CD} /$ dipolarization leading to WEJ expanding into the 17:00-18:00 MLT sector recorded by IMAGE chain magnetograms; (v) plasma injection to the partial ring current resulting in SYM-H dip and enhanced R2-type FAC coupling to the EEJ in Harang regionsouth at dusk; (vi) the large spatial scales $\left(L_{X}\right.$ and $\left.L_{Y}\right)$ of the $\mathrm{CD} /$ dipolarization process contributing to large inductive plasma sheet electric fields $\left(\sim 2.5 \mathrm{mV} \mathrm{m}^{-1}\right)$ and associated momentum coupling to the polar cap ionosphere $\left(\Delta \mathrm{CPCP}=(0.1-0.2) E_{\mathrm{PS}} \cdot L_{Y} ; E_{\mathrm{PS}}=\left(\Delta B_{z} / \Delta t\right) \cdot L_{X}\right)$, leading to the observed PCN night enhancements in the initial phase ( $\left.\triangle \mathrm{PCN} \approx 0.8 E_{\mathrm{PS}}\right)$; and (vii) BBFs in the phase of $\mathrm{AL}$ partial recovery with associated M-I coupling in two consecutive stages: (1) plasma sheet-R1 FAC coupling to Harang region-north (current wedgelets-auroral streamers) in stage 1 (mid-tail) and (2) FAC coupling to Harang regionsouth (enhanced EEJ and intensified southern branch auroral precipitation) in stage 2 (BBFs in braking phase).

Feature iii, involving dipolarizations related to activations of the SCW (Bostrøm type I system), is observed from spacecraft GOES-10 in the interval 05:00-12:00 UT (see Fig. 10). We note that one of the activations of the Bostrøm type II current system at dawn is observed by GOES-10 $\left(\delta B_{x}<\right.$ $0 / \delta B_{y}>0$ events) at the same time (14:10-14:20 UT) as an 
impulsive ground signature of this type of current system (EEJ enhancement) is observed at dusk, in Harang regionsouth.

Feature vii, i.e., the presence of smaller-scale plasma sheet events during the phase of AL partial recovery, is consistent with the results of Nakamura et al. (1999): "The flux transport in the midtail takes place as a large-scale phenomenon during the expansion phase but is a more localized and patchy phenomenon during the recovery phase for a substorm with prolonged IMF input." The BBFs in the braking phase are expected to add to the partial ring current and contribute to strengthening the R2 FAC and the ionospheric Pedersen current closure in the ionosphere (and thereby enhancing the EEJ) in Harang region-south, as we document in our ground-satellite observations at dusk. The magnetospheric part of this phenomenon has been predicted by Yang et al. (2012) and Birn and Hesse (2013).

The partial recovery of SYM-H typically appearing after the plasma injection events (SYM-H dips-field dipolarizations) is explained in terms of a shielding effect (so-called "overshielding") originating from the ionospheric closure of R2 FAC at subauroral latitudes, i.e., an eastward-directed ionospheric current at low and mid-latitudes driven by R2 FACs (see Ritter and Lühr, 2008, their Fig. 15). This M-I coupling leads to a reduction of the Volland-Stern electric field $\left(E_{\mathrm{VS}}\right)$ and thereby prohibits the deep plasma injection to the ring current. It therefore contributes to a reduction of the PRC and the associated SYM-H partial recovery ( $\delta$ SYM$\left.\mathrm{H} / \delta t=-a E_{\mathrm{VS}}\right)$.

\section{Summary}

We reported ground-satellite conjunction studies of $\mathrm{M}-\mathrm{I}$ coupling across the auroral oval at dusk (17:00-18:00 MLT) and near midnight (20:00-03:00 MLT) during a long interval of continued strong solar wind forcing by an interplanetary CME passing Earth on 18 August 2003. This approach allowed us to document the evolution of the two-component substorm current system referred to as the Bostrøm types I-II system and the state of polar cap convection via the PCN index. We emphasized the multistage evolution of substorm activity where the expansion phase consists of two distinct substages. These are an initial transient phase and a later persistent phase which, according to our findings, are dominated by inductive and potential electric field coupling, respectively. The initial transient stage is characterized by (i) current disruption $(\mathrm{CD}) /$ magnetic field dipolarization detected in the near-Earth (geostationary altitude; GOES-10 data) plasma sheet with extension of magnetic perturbations to the tail lobes $\left(X=-11\right.$ to $-18 R_{\mathrm{E}}$; Geotail and Cluster data not shown here), (ii) abrupt intensification-poleward expansion of the westward electrojet (WEJ) in the evening-midnight sector (Alaska sector magnetometer data) followed by (iii) abrupt intensification of the eastward electrojet (EEJ) at dusk in Harang region-south, (iv) rapid westward expansion of the WEJ beyond the 18:00 MLT meridian (Harang regionnorth), as documented by IMAGE chain magnetograms (Svalbard-Scandinavia-Finland-Russia), and (v) a 1020 min-long monotonic rise of the PCN index.

The subsequent persistent phase is characterized by (i) a double-oval configuration with a series of WEJ activations and auroral streamer activity with associated R1-type FAC coupling in Harang region-north (at dusk), (ii) EEJ activity and R2-type FAC coupling in Harang region-south (at dusk), (iii) a persistent high-level (plateau) or slowly decreasing PCN index, and (iv) bursty bulk flows (BBFs) in the mid-tail plasma sheet (Geotail data not shown). We make quantitative estimates of the contributions to the excitation of polar cap convection (PCN index) and the cross-polar-cap potential (CPCP), from inductive electric fields in the initial transient stage of the expansion phase. We find that inductive electric fields are important in association with these major substorm dipolarizations. This is due to a combination of the dipolarization rate $\left(\Delta B_{z} / \Delta t\right)$ and the large spatial scales of the dipolarization (current disruption) process as inferred from ground and satellite observations in our case. The persistent phase is dominated by strong potential electric field coupling, most likely associated with the integrated effect of $V_{x} \cdot B_{z}$ enhancement events (BBFs/dipolarization fronts) created by an active magnetotail reconnection process. When we emphasize the distinction between the initial transient phase versus the persistent phase, we apply a terminology previously used to describe M-I coupling in the dayside magnetosphere which is triggered by north-to-south turnings of the IMF (Siscoe et al., 2011).

Acknowledgements. We thank Truls Lynne Hansen, Ari Viljanen and the Finnish Meteorological institute for operating the IMAGE chain magnetometers in Svalbard-Scandinavia (http-address: www.geo.fmi.fi/image). The Poker Flat magnetometer (Fig. 11) is operated by the Geophysical Institute, University of Alaska, Fairbanks. Work at University of Oslo is supported by the Norwegian Research Council (NFR). Work at UNH is supported by NASA grant NNX13AP39G.

Topical Editor L. Blomberg thanks A. Kullen and one anonymous referee for their help in evaluating this paper.

\section{References}

Akasofu, S.-I.: The development of the auroral substorm, Planet. Space Sci., 12, 273-282, 1964.

Akasofu, S.-I.: The relationship between the magnetosphere and magnetospheric/auroral substorms, Ann. Geophys., 31, 387-394, doi:10.5194/angeo-31-387-2013, 2013.

Andalsvik, Y. L., Sandholt, P. E., and Farrugia, C. J.: Dayside and nightside contributions to cross-polar cap potential variations: the 20 March 2001 ICME case, Ann. Geophys., 29, 2189-2201, doi:10.5194/angeo-29-2189-2011, 2011. 
Andalsvik, Y., Sandholt, P. E., and Farrugia, C. J.: Substorms and polar cap convection: the 10 January 2004 interplanetary CME case, Ann. Geophys., 30, 67-80, doi:10.5194/angeo-30-67-2012, 2012.

Baumjohann, W., Paschmann, G., and Nagai, T.: Thinning and expansion of the substorm plasma sheet, J. Geophys. Res., 97, 17173-17175, 1992.

Baumjohann, W., Hesse, M., Kokubun, S., Nagai, T., and Petrukovich, A. A.: Substorm dipolarization and recovery, J. Geophys. Res., 104, 24995-25000, 1999.

Benkevich, L., Lyatsky, W., and Cogger, L. L.: Field-aligned currents between conjugate hemispheres, J. Geophys. Res., 105, 27727-27737, 2000.

Birn, J. and Hesse, M.: The substorm current wedge in MHD simulations, J. Geophys. Res., 118, 3364-3376, doi:10.1002/jgra.50187, 2013.

Bostrøm, R.: A model of the auroral electrojets, J. Geophys. Res., 69, 4983-4999, 1964.

Bostrøm, R.: Current systems in the magnetosphere and ionosphere, in: Radar Probing of the Auroral Plasma, edited by: Brekke, A., 257-284, Universitetsforlaget, Troms $\emptyset$-Oslo-Bergen, 1977.

Brekke, A.: The relationship between the Harang discontinuity and the substorm injection boundary, Planet. Space Sci., 25, 11191134, 1977.

Burke, W. J., Gentile, L. C., and Huang, C. Y.: Penetration electric fields driving main phase Dst, J. Geophys. Res., 112, A07206, doi:10.1029/2006JA012137, 2007.

Cai, X., Henderson, M. G., and Clauer, C. R.: A statistical study of magnetic dipolarization for sawtooth events and isolated substorms at geosynchronous orbit with GOES data, Ann. Geophys., 24, 3481-3490, doi:10.5194/angeo-24-3481-2006, 2006.

Cao, J.-B., Yan, C., Dunlop, M., Reme, H., Dandouras, I., Zhang, T., Yang, D., Moiseyev, A., Solovjev, S. I., Wang, Z. Q., Leonoviche, A., Zolotukhina, N., and Mishin, V.: Geomagnetic signatures of current wedge produced by fast flows in the plasma sheet, J. Geophys. Res., 115, A08205, doi:10.1029/2009JA014891, 2010.

Chen, C. X. and Wolf, R. A.: Interpretation of high-speed flows in the plasma sheet, J. Geophys. Res., 98, 21409-21419, 1993.

Crooker, N. U., Toffoletto, F. R., and Gussenhoven, M. S.: Opening the cusp, J. Geophys. Res., 96, 3497-3503, 1991.

Fairfield, D. H. and Scudder, J. D.: Polar rain: Solar coronal electrons in the Earth's magnetosphere, J. Geophys. Res., 90, 40554068, 1985.

Fairfield, D. H., Mukai, T., Brittnacher, M., Reeves, G. D., Kokubun, S., Parks, G. K., Nagai, T., Matsumoto, H., Hashimoto, K., Gurnett, D. A., and Yamamoto, T.: Earthward flow bursts in the inner magnetotail and their relation to auroral brightenings, akr intensifications, and geosynchronous particle injections and magnetic activity, J. Geophys. Res., 104, 355-370, 1999.

Farrugia, C. J., Freeman, M. P., Burlaga, L. F., Lepping, R. P., and Takahashi, K.: The Earth's magnetosphere under continued forcing: Substorm activity during the passage of an interplanetary magnetic cloud, J. Geophys. Res., 98, 7657-7671, 1993.

Frissell, N. A., Baker, J. B. H., Ruohoniemi, J. M., Clausen, L. B. N., Kale, Z. C., Rae, I. J., Kepko, L., Oksavik, K., Greenwald, R. A., and West, M. L.: First radar observations in the vicinity of the plasmapause of pulsed ionospheric flows generated by bursty bulk flows, Geophys. Res. Lett., 38, L0113, doi:10.1029/2010GL045857, 2011.
Gao, Y., Kivelson, M. G., Walker, R. J., and Weygand, J. M.: Long-term variation of driven and unloading effects on polar cap dynamics, J. Geophys. Res., 117, A02203, doi:10.1029/2011JA017149, 2012.

Gjerloev, J. W. and Hoffman, R. A.: The convection electric field in substorms, J. Geophys. Res., 106, 12919-12931, 2001.

Gordeev, E. I., Sergeev, V., Pulkkinen, T. I., and Palmroth, M.: Contribution of magnetotail reconnection to the cross-polar cap electric potential drop, J. Geophys. Res., 116, A08219, doi:10.1029/2011JA016609, 2011.

Haerendel, G.: Six auroral generators, J. Geophys. Res., 116, A00K05, doi:10.1029/2010JA016425, 2011.

Harang, L.: The mean field of disturbance of the polar earthmagnetic storm, Geofys. Publ., 16, 12-56, 1946.

Henderson, M. G., Reeves, G. D., and Murphree, J. S.: Are northsouth aligned auroral structures an ionospheric manifestation of bursty bulk flows?, Geophys. Res. Lett., 25, 3737-3740, 1998.

Henderson, M. G., Skoug, R., Donovan, E., Thomsen, M. F., Reeves, G. D., Denton, M. H., Singer, H. J., McPherron, R. L., Mende, S., Immel, T. J., Sigwarth, J. B., and Frank, L. A.: Substorms during the 10-11 August 2000 sawtooth event, J. Geophys. Res., 111, A06206, doi:10.1029/2005JA011366, 2006.

Heppner, J. and Maynard, N. C.: Empirical high-latitude electric field models, J. Geophys. Res., 92, 4467-4489, 1987.

Heppner, J. P.: The harang discontinuity in auroral belt ionosphric currents, Geofys. Publ., 29, 105-120, 1972.

Jacquey, C. and Sauvaud, J. A.: Dynamics of the cross-tail current during a long period of enhanced energy input from the solar wind to the magnetosphere, in SUBSTORMS 1, ESA SP-335, 155-163, Kiruna, Sweden, 1992.

Kan, J. R. and Lee, L. C.: Energy coupling function and solar windmagnetosphere dynamo, Geophys. Res. Lett., 6, 577-580, 1979.

Kauristie, K., Syrjasuo, M. T., Amm, O., Viljanen, A., Pulkkinen, T. I., and Opgenorth, H.: A statistical study of evening sector arcs and electrodynamics, 28, 1605-1610, 2001.

Klimas, A. J., Valdivia, J. A., Vassiliadis, D., Baker, D. N., Hesse, M., and Takalo, J.: Self-organized criticality in the substorm phenomenon and its relation to localized reconnection in the magnetospheric plasma sheet, J. Geophys. Res., 105, 18765-18780, 2000.

Koskinen, H. and Pulkkinen, P.: Midnight velocity shear zone and the concept of Harang discontinuity, J. Geophys. Res., 100, 9539-9547, 1995.

Kullen, A., Ohtani, S., and Karlsson, T.: Geomagnetic signatures of auroral substorms preceded by pseudobreakups, J. Geophys. Res., 114, A04201, doi:10.1029/2008JA013712, 2009.

Kullen, A., Karlsson, T., Cumnock, J. A., and Sundberg, T.: Occurrence and properties of substorms associated with pseudobreakups, J. Geophys. Res., 115, A12310, doi:10.1029/2010JA015866, 2010.

Lopez, R. E. and Freeman, J. W.: Solar wind proton temperaturevelocity relationship, J. Geophys. Res., 91, 1701-1705, 1986.

Lyons, L. R., Nagai, T., Blanchard, G. T., Samson, J. C., Yamamoto, T., Mukai, T., Nishida, A., and Kokubun, S.: Association between Geotail plasma flows and auroral poleward boundary intensifications observed by CANOPUS photometers, J. Geophys. Res., 104, 4485-4500, 1999. 
Lyons, L. R., Wang, C. P., and Nagai, T.: Substorm onset by plasma sheet divergence, J. Geophys. Res., 108, 1427, doi:10.1029/2003JA010178, 2003.

Lyons, R. L., Nishimura, Y., Xing, X., Runov, A., Angelopoulos, V., Donovan, E., and Kikuchi, T.: Coupling of dipolarization front flow bursts to substorm expansion phase phenomena within the magnetosphere, J. Geophys. Res., 117, A02212, doi:10.1029/2011JA017265, 2012.

Marghitu, O., Karlsson, T., Klecker, B., Haerendel, G., and McFadden, J.: Auroral arc and electrodynamics in the Harang region, J. Geophys. Res., 114, A03214, doi:10.1029/2008JA013630, 2009.

Marklund, G.: Auroral arc classification scheme based on the observed arc-associated electric field pattern, Planet. Space Sci., 32, 193-211, 1984.

McPherron, R. L., Russell, C. T., and Aubry, M. A.: Satellite studies of magnetospheric substorms on august 15, 1968, 9, phenomenological model for substorms, J. Geophys. Res., 78, 3131-3149, 1973.

McPherron, R. L., Hsu, T.-S., Kissinger, J., Chu, X., and Angelopoulos, V.: Characteristics of plasma flows at the inner edge of the plasma sheet, J. Geophys. Res., 116, A00I33, doi:10.1029/2010JA015923, 2011.

Nakamura, R., Bargatze, L. F., Mukai, T., Nagai, T., Baker, K. B., Hairston, M. R., Reiff, P. H., Petrukovich, A. A., Nozdrachev, M., and Troshichev, O. A.: Response of midtail electric field to enhanced solar wind energy input, J. Geophys. Res., 104, 1729917310, 1999.

Nielsen, E. and Greenwald, R. A.: Electron flow and visual aurora at the Harang discontinuity, J. Geophys. Res., 84, 4189-4200, 1979.

Nishimura, Y., Lyons, L., Zou, S., Angelopoulos, V., and Mende, S.: Substorm triggering by new plasma intrusion: Themis all-sky imager observations, J. Geophys. Res., 115, A0722, doi:10.1029/2009JA015166, 2010.

Provan, G., Milan, S. E., Lester, M., Yeoman, T. K., and Khan, H.: Letter to the Editor Simultaneous observations of the ionospheric footprint of flux transfer events and dispersed ion signatures, Ann. Geophys., 20, 281-287, doi:10.5194/angeo-20-281-2002, 2002.

Pudovkin, M. I., Semenov, V. S., Starkov, G. V., and Kornilova, T. A.: On separation of potential and vortex parts of the magnetotail electric field, Planet. Space Sci., 39, 563-568, 1991.

Reiff, P. H., Spiro, R. R., and Hill, T.: Dependence of polar cap potential on interplanetary parameters, J. Geophys. Res., 86, 76397648, 1981.

Richardson, I. G. and Cane, H. V.: Near-Earth interplanetary coronal mass ejections during solar cycle 23 (1996-2009): Catalog and summary of properties, Solar Phys., 264, 189-237, 2010.

Ritter, P. and Lühr, H.: Near-Earth magnetic signature of magnetospheric substorms and an improved substorm current model, Ann. Geophys., 26, 2781-2793, doi:10.5194/angeo-26-27812008, 2008.

Rostoker, G.: Midlatitude transition bays and their relation to spatial movement of overhead current system, J. Geophys. Res., 71, 7995, 1966.

Sandholt, P. E. and Farrugia, C. J.: Poleward moving auroral forms (PMAFs) revisited: responses of aurorae, plasma convection and Birkeland currents in the pre- and postnoon sectors under posi- tive and negative IMF By conditions, Ann. Geophys., 25, 16291652, doi:10.5194/angeo-25-1629-2007, 2007.

Sandholt, P. E. and Farrugia, C. J.: Plasma flow channels at the dawn/dusk polar cap boundaries: momentum transfer on old open field lines and the roles of IMF By and conductivity gradients, Ann. Geophys., 27, 1527-1554, doi:10.5194/angeo-271527-2009, 2009.

Sandholt, P. E., Deehr, C. S., Egeland, A., Lybekk, B., Viereck, R., and Romick, G. J.: Signatures in the dayside aurora of plasma transfer from the magnetosheath, J. Geophys. Res., 91, 1006310079, 1986.

Sandholt, P. E., Farrugia, C. J., Lester, M., Cowley, S. W. H., Milan, S., Denig, W. F., Lybekk, B., Trondsen, E., and Vorobjev, V.: Multistage substorm expansion: Auroral dynamics in relation to plasma sheet particle injection, precipitation, and plasma convection, J. Geophys. Res., 107, 1342, doi:10.1029/2001JA900116, 2002.

Sandholt, P. E., Andalsvik, Y., and Farrugia, C. J.: Polar cap convection/precipitation states during Earth passage of two ICMEs at solar minimum, Ann. Geophys., 28, 1023-1042, doi:10.5194/angeo-28-1023-2010, 2010.

Sandholt, P. E., Andalsvik, Y. L., and Farrugia, C. J.: The pulsed nature of the nightside contribution to polar cap convection: repetitive substorm activity under steady interplanetary driving, Ann. Geophys., 30, 1539-1553, doi:10.5194/angeo-30-15392012, 2012.

Nakamura, R., Bargatze, L. F., Mukai, T., Nagai, T., Baker, K. B., Hairston, M. R., Reiff, P. H., Petrukovich, A. A., Nozdrachev, M., and Troshichev, O. A.: A study of the near-Earth plasma sheet and lobe driven by multiple substorms: Comparisons with a full particle simulation of reconnection, J. Geophys. Res., 117, AO1221, doi:10.1029/2011JA017033, 2012.

Sergeev, V. A., Liou, K., Newell, P. T., Ohtani, S.-I., Hairston, M. R., and Rich, F.: Auroral streamers: characteristics of associated precipitation,convection and field-aligned currents, Ann. Geophys., 22, 537-548, doi:10.5194/angeo-22-537-2004, 2004.

Sergeev, V. A., Tsyganenko, N. A., Smirnov, M. V., Nikolaev, A. V., Singer, H. J., and Baumjohann, W.: Magnetic effects of the substorm current wedge in a "spread-out-wire" model and their comparison with ground, geosynchronous, and tail lobe data, J. Geophys. Res., 116, A07218, doi:10.1029/2011JA016471, 2011.

Sergeev, V. A., Angelopoulos, V., and Nakamura, R.: Recent advances in understanding substorm dynamics, Geophys. Res. Lett., 39, L0511, doi:10.1029/2012GL050859, 2012.

Siscoe, G. L., Farrugia, C. J., and Sandholt, P. E.: Comparison between the two basic modes of magnetospheric convection, J. Geophys. Res., 116, A05210, doi:10.1029/2010JA015842, 2011.

Southwood, D. J.: The ionospheric signature of flux transfer events, J. Geophys. Res., 92, 3207-3213, 1987.

Tanaka, T., Nakamizo, A., Yoshikawa, A., Fujita, S., Shinagawa, H., Shimazu, H., Kikuchi, T., and Hashimoto, K. K.: Substorm convection and current system deduced from the global simulation, J. Geophys. Res., 115, A05220, doi:10.1029/2009JA014676, 2010.

Troshichev, O. and Janzhura, A.: Relationship between the PC and $\mathrm{AL}$ indices during repetitive bay-like magnetic disturbances in the auroral zone, J. Atmos. Sol. Terr. Phys., 71, 1340-1352, 2009. 
Troshichev, O., Stauning, P., Liou, K., and Reeves, G.: Saw-tooth substorms: Inconsistency of repetitive bay-like magnetic disturbances with behaviour of aurora, 47, 702-709, 2011.

Troshichev, O. A., Lukianova, R. Y., Papitashvili, V. O., Rich, F. J., and Rasmussen, O.: Polar cap index (PC) as a proxy for ionospheric electric field in the near-pole region, Geophys. Res. Lett., 27, 3809-3812, doi:10.1029/2000GL003756, 2000.

Vorobjev, V. G., Yagodkina, O. I., and Katkalov, Y. V.: Auroral Precipitation Model and its application to ionospheric and magnetospheric studies, J. Atmos. Sol.-Terr. Phys., 102, 157-171, 2013.

Weygand, J. M., McPherron, R. L., Frey, H. U., Amm, O., Kauristie, K., Viljanen, A., and Koskinen, H.: Relation of substorm onset to Harang discontinuity, J. Geophys. Res., 113, A04213, doi:10.1029/2007JA012537, 2008.

Yagodkina, O. I., Despirak, I. V., and Vorobjev, V. G.: Spatial distribution of auroral precipitation during storms caused by magnetic clouds, J. Atmos. Sol.-Terr. Phys., 77, 1-18, 2012.
Yang, J., Toffoletto, F. R., Wolf, R. A., Sazykin, S., Ontiveros, P. A., and Weygand, J. M.: Large-scale current systems and ground magnetic disturbance during deep substorm injections, J. Geophys. Res., 117, A04223, doi:10.1029/2011JA017415, 2012.

Yau, Z. H., Angelopoulos, V., Pu, Z. Y., Fu, S. Y., Kubyshkina, M., Liu, J., Chu, X. N., Nishimura, T., Cao, X., Du, A. M., Shi, Q. Q., and Wei, Y.: Conjugate observations of flow diversion in the magnetotail and auroral arc extension in the ionosphere, J. Geophys. Res., 118, 4811-4816, doi:10.1002/jgra.50419, 2013.

Zou, S., Lyons, L. R., Wang, C.-P., Boudouridis, A., Ruohoniemi, J. M., Anderson, P. C., Dyson, P. L., and Devlin, J. C.: On the coupling between the Harang reversal evolution and substorm dynamics: A synthesis of SuperDARN, DMSP, and IMAGE observations, J. Geophys. Res., 114, A01205, doi:10.1029/2008JA013449, 2009. 